\title{
Article \\ Smart Regions in the Italian context. From a theoretical to an empirical framework
}

\author{
Daniela Cialfi (10)
}

\begin{abstract}
Department of Philosophical, Pedagogical and Economic-Quantitative Sciences, Section of Economics and Quantitative Methods, University of Chieti-Pescara, Pescara (Italy); daniela.cialfi@unich.it
\end{abstract}

\begin{abstract}
The present study aims to examine the role the social and digital infrastructures might have during the building process of the Smart Regions in the Italian context. Within this framework, it is possible to identify some essential research questions, such as why the same regions are growing faster than the other and which type of effects could be generated from the different connectivity between the regions. Since the Smart Region concept is still composed of technical reports, pilot projects and experiences from a limited number of cities on the international stage, this work it is tried to use a new approach, applying either a neuronal model, the Self-Organizing Maps, and the La Fuente (1995) multivariate regression approach, to extrapolate the existence of possible future conditions for the rising of Smart Regions in Italy, studying the evolution of the used database during the period 2005 - 2016. From the analysis what emerged is that the only bridging social capital dimension, empirically speaking, feed the regional innovation growth because the structure of social relationship facilitates interactions across social, political and economic agents; but there are institutional deficits, most pronounced in Italy and other European countries.
\end{abstract}

Keywords: smart regions; social capital; ICT; neural network; regional performance; Italy

\section{Introduction}

The world is changing because of the rising of a new type of regions: knowledgeintensive, innovative, and intelligent regions. Knowledge has always seen as a critical input to production and as one of the focal driven forces for capital competition as stated by Dicken (2007) in his work of 2007. All of these elements are the essential characteristics of the knowledge society configuring it as a driver of economic and social development. 1 Thus, in the knowledge society, being able to realise high - intensity knowledge products, the availability and use of sophisticated knowledge are crucial instruments for the enterprises' competitiveness, social life, economy and education. This new global setting is linked to a new development triad: knowledge-based, innovation-led economies and intelligent agglomerations. In this scenario, as said at the beginning, regions are transforming themselves and, at the same time, the concepts of core and periphery are also changing: the core is what holds knowledge and technology, and the periphery is the venue of the standardised forms of production with low added value and complexity. In the periphery, according to Hall (2003), innovation plays a critical role because it could improve productivity and wealth, both in manufacturing and the services sectors. This shaping of core-periphery is immediately reflected into the regional policies, such as the Regional Innovation Strategies, (RIS) or the Regional Innovation and Technology Transfer Strategies (RITTS).

According to Sassen (2003), the new role of regions in the knowledge-led society rotated

1 Instead of capital and labour, information and knowledge have many characteristics of what economists call public goods: once discovered and made public, knowledge could be shared at the minor cost, and its values are not depleted in consumption (non-rival). Indeed, the economic and social value of knowledge increases as it is shared with and used by others. 
around the power of spatial agglomeration to create systems in which knowledge and skills are synthesised across the population. In this context, regions assume the forms of polycentric systems of innovative clusters within networks of knowledge and technology linking the R \& D institutions and intermediates. Within this framework, the principal strategy could be the development of Smart Regions. ${ }^{2}$ Its aim is to generate a stimulus to the present strengths in order to identify hidden opportunities and generate platforms in which regions might build competitive advantages into a knowledge-based society. One of the main scopes of the present analysis is to examine the possible role might have the social and digital infrastructures during the building process of the Smart Regions in the Italian context. Furthermore, it is possible to identify some essential research questions, such as why the same regions are growing faster than the another and which type of effects could be generated from the different connectivity between the regions. In order to be able to answer those questions as fully as possible, the present research work will be structured in three sections, as follows. Section 2 will be oriented towards the issues concerning, for its first part, the role of the innovation into the regional development and after, in its second part it will be introduced the Smart Region concept. Next, section 3 shows an empirical application of the concepts examined in the previous section to the Italian context and section 4 provides a concluding remarks.

\section{Geography of innovation: Smart Regions}

The aim of this section is to held assumptions within economic geography concerning the relationship between knowledge spillovers, technology, R \& D and innovation. A question arises: Is it possible to recognise a connection between the Intelligent and Smart Region concept and the innovation literature? A possible answer to this question might be yes since the double nature of digital space itself. On the one hand, it offers conditions for creating smart regions, introducing disruptive innovations into regions and driving a series of radical changes in the relationship between the population and the regional environment. On the other one, instead, the same digital space strengthens the mechanisms of innovation at work in regions, extending the innovation systems formed at regional scales. ${ }^{3}$

Section is structured as follows. The next sub-section 2.1 reviews the literature on the nature, role and links between $\mathrm{R} \& \mathrm{D}$, innovation and productivity, discussing the characteristics of knowledge and technological regimes in the shaping process of the firm's innovative behaviour's evolution. Following, sub-section 2.2 examines the link between knowledge and its geography by stressing different starting points between the activity (the characterisation of knowledge) and its context (the region). Sub-section ?? is focused on the spatial dimensions of knowledge diffusion introducing the concept of intelligent/smart regions. ${ }^{4}$

\subsection{The role played by geographical and non-geographical actors into regional innovation}

According to Schumpeter (1934)'s primary competition argument, all entrepreneurial innovations will be economically convenient as long as they are not immediately copied since innovation creates monopoly rents. In this context, innovation has been seen as the outcome of a collision between technological opportunities and user needs; shaping itself

2 This concept rose, according to Kroll (2015) in response of the EU exigency of one-size-fits-all policy that focused on national state perspective rather than the regional one; but regions in the European Union have different economic and institutional structures.

3 The regional innovation system approach figures out because of the discussions about the factors that shapes knowledge and innovation capacities generation within regions themselves. Furthermore, the innovation system approach moves away from a linear model recognising that innovation typically results from a complex, interactive and cumulative knowledge and learning processes in which a variety of actors participate. In particular, the RIS approach emphasized the importance of geographical proximity for knowledge transfer and learning.

4 According to the European Commission, the Smart Region serves to enhance the capacity of regions to support and generate innovation- related interactions and collaborations. 
as a critical dimension of economic value creation. ${ }^{5}$ Generally speaking, innovation can be distinguished into the following dimensions:

- Type: technological product and process innovation or non-technological-organisational innovation;

- $\quad$ Mode: never innovation (strategic and intermittent), technology modifier and technology adapter;

- Socio-economic impact: incremental or disruptive.

Within this theoretical framework, the role of R \& D in stimulating innovation has viewed as central for economic performance and social welfare. One way of making progress on those issues is understanding the role played by knowledge and its creation process. Helping to understand this process, there is the notion of absorptive capacity. Absorptive capacity, according to Cohen (1989), is the '[... ] ability by a firm to identify, assimilate and exploit knowledge from external environment [... ]' (Cohen (1989), p. 569). In particular, authors have affirmed that the absorptive capacity could be seen as a function of the previous R \& D investment of the firm. Moving on, in this model they focused on the idea that the creation of absorptive capacity could be a path-dependent process because the absorptive capacity permits to anticipate the nature of the possible technological advancement. As a consequence of this, this phenomena could bring to an advanced position regarding the potential lock-out of firms. ${ }^{6}$ In this framework, regional absorptive capacity could be defined as '[...] more than just the sum of the absorptive capacities of the individual firms located in the region [... ]'(Cooke et al. (2011), p. 216). As it is possible to look at the previous definition, the aim of the studies about the absorptive capacity at the regional level is to estimate regional knowledge production function trying to incorporate factors of absorptive capacity at the regional level.

In this context, links between knowledge, innovation and economic geography are complex: on one side it is present a cluster's phenomenon associated with local knowledge spillovers, in the sense of externalities, occurs in situations of pure agglomeration in which markets are present. On the other side, instead, we have local industries which are primly oligopolistic where knowledge transactions within industrial complexes are mediated via long-term legal contracts between groups of firms.

From the previous example emerge the existence of a widespread consensus in academic and policy debates that knowledge and innovation are essential for securing competitiveness, dynamic growth and prosperity of regional economies. What distinguishes the regions of innovation excellence from other regions? Their capability to boost the innovation performance of the organisation in which have established themselves. This extra strength derives from the territory, the people and the resources. For this reason, some R \& D enterprises choose their location into the most technologically advanced regions. In this context, the Regional Innovation System (RIS hereafter) approach figures out into the discussion about the variables that shape the knowledge generation and innovation capacities of regions. So, why it was necessary to apply a systems perspective at the regional level? Since RIS emphasises the importance of geographical proximity for knowledge transferring and learning, on the one hand, and at the same time, it legitimises the study of the innovation systems from a regional perspective on the other. With these characteristics, an investigation at the regional level perspective of innovation system is justified.

5 In the last decades, this research approach has been replaced by a new theoretical paradigm called endogenous growth theory, which suggests that economic outputs are positively correlated with the growth of new products, radical or incremental. Furthermore, in emphasising innovation, it is essential to remember that innovation based on imitation or technology transfer can also be the result of substantial productivity growth of economies. This line of thought is closely linked with the idea that by engaging in R \& D in a active way, and in particular in the intellectual or technological field, where once this amount of knowledge is acquired, it can help in understanding and assimilating more easily the discoveries of others.

6 This allows to exalt the importance of the non-superficial knowledge and the magnitude of the knowledge. More specifically, it is about the knowledge's diversification that allows the creation of new and original connections' settings. 


\title{
2.2. Relatedness and knowledge
}

As could be seen in the previous sub-section, knowledge plays a vital role in explaining the geography of innovation. This sub-section aims to answer the following question: why does this innovation take place in this region and not elsewhere.

A possible answer derives from the evolutionary way of thinking where the spatial dynamics of knowledge are understood as cumulative, path-dependent and interactive. As a result, a primary driving force is the relatedness concept: relatedness between actors could affect the nature and scope of knowledge spillovers, so, the relatedness's degree and nature might differ from region to region. ${ }^{7}$ From this perspective, the evolution of knowledge, in space and time, is the result of complex and non-linear dynamics, emerging out of interactions between actors that have different capabilities under the following hypothesis:

- Hypothesis 1: Regions could develop new specialisations in technological activities that are related to their knowledge bases;

- Hypothesis 2: Regions might experience technological growth in technological activities that are related to their knowledge bases;

Thus, as it is possible to see from the previous hypothesis, the dynamics of knowledge production and technological change are therefore conceptualised as a cumulative, path-dependent and interactive process. In this Schumpeterian view of innovation and technological change, new knowledge items do not emerge randomly, and its production is not an isolated effect.

To conclude this sub-section, it is possible to stress out how literature does not focus on how much a region produces but on how it produces.The network-based representation of the knowledge structures of regions could be seen as a way to formalise the concept of relatedness and to systematically test its implication for the evolution of the geography of innovation. Furthermore, mapping the knowledge space of regions would be very informative for policymakers about the evolution of what kind of technological development are within the region (closely related to pre-existing knowledge) and which are risky jumps (far from the skills and competencies of the region).

\section{Smart Regions in the Italian context: Is it possible?}

\begin{abstract}
"Society can only move forward as fast as it innovates. It can only provide lasting prosperity if it makes the most of the knowledge, entrepreneurial spirit and productivity of its people." (Informal EU Leaders' meeting on innovation in Sofia on 16 May 2018)
\end{abstract}

As it is possible to stress out from the previous section of this work that Smart Regions concept is still under development because of the fact that, unlike the Smart City concept, the Smart Region is still composed by technical reports, pilot projects and experiences from a limited number of cities in the international stage. That is why this section could offer a new approach, using either a neuronal model and the La Fuente and Vives (1995) multivariate regression approach, to extrapolate the existence of possible future conditions for the rising of Smart Regions in Italy, studying the evolution of the database used. This section is divided into three sub-sections. The first reflects on the European and regional innovation framework focusing the attention on the Italian position in Europe. The second section covers the methodological part of the present chapter's aim. In particular, it presents the two statistical tools, the Self-Organizing Maps

\footnotetext{
7 According to Boschma (2005), being proximate means intensify the probability of agents to interact and efficiently exchange knowledge because knowledge has an architecture based on similarities and differences
} 
and the regression model; and the database used for the analysis during the period 2005 - 2016. The last section provides the results and lays out the possible future research areas for the Italian context.

\subsection{The European and regional innovation framework: the Italian position}

For having a measurement of the strengths or weaknesses of the European and regional innovation systems, the annual European Innovation Scoreboard 2018 (EIS hereafter) and the Regional Innovation Scoreboard 2017 (RIS hereafter) ${ }^{8}$ provide a comparative assessment of the research and innovation performance of the European Member States at national and regional level respectively. Starting for the national level, and after at the regional one, it is possible to see improving performance and progress acceleration correlated with a positive outlook: the innovation performance continues to increase by 5.8 points since 2010. It is in progress a catching - up phenomenon with the United States of America, Japan and Canada; but there is not convergence process between the European Union countries because some countries are performing at lower levels and others at higher levels.

Based on their average performance scores, calculated by a composite indicator, the Summary Innovation Index, ${ }^{9}$ the European Union Member States could be divided into four different performance group:

1. Innovation Leaders: Denmark, Finland, The Netherland, Sweden and United Kingdom;

2. Strong Innovators: Austria, Belgium, France, Germany, Ireland and Slovenia;

3. Moderate Innovators:Italy, Croatia, Cyprus, Czech Republic, Estonia, Greece, Hungary, Latvia, Lithuania, Malta, Portugal, Slovakia and Spain;

4. Modest Innovators: Bulgaria and Romania.

As it is possible to see, Figure 3.1 below shows the performance of the European Union national innovation system according to the score of the Summary Index in 2017.

8 The Regional Innovation Scoreboard accompanies the European Innovation Scoreboard comparing the performance of the innovation system across 220 regions of 22 Member States at NUTS 2 level. It is less frequent and less detailed due to the general lack of innovation data at the regional level.

9 This index is a composite indicator obtained by taking into account a unweighted average of 27 indicators. It summarizes the performance of a range of different indicators, distinguishing them between four types of variables:

1. 1. Framework conditions which indicates the main drivers of innovation performance external to the firms, differencing between three innovation resources:

- $\quad$ Human resources;

- $\quad$ Attractive research systems;

- Innovation-friendly environment.

2. Investments made in both public and private sectors:

- $\quad$ Finance and support;

- $\quad$ Firm investments.

3. Innovation activities which capture the different aspects of innovation in the business sector and differencing between three dimensions:

- Innovators;

- Linkages;

- Intellectual assets.

4. Impact of firm's innovation activities

- $\quad$ Employment impacts;

- Sales impacts. 
Figure 1. Performance of FI T Memher States' innovation svetems

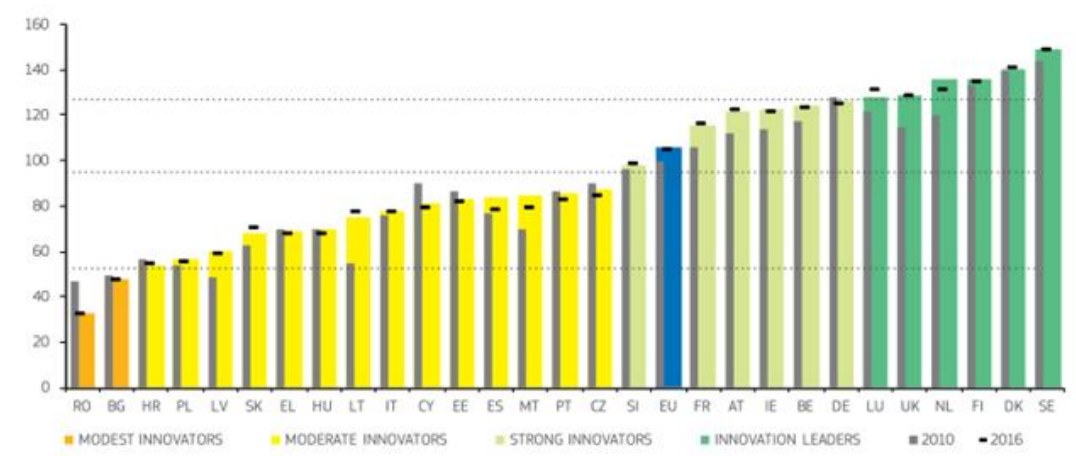

Source: European Innovation Scoreboard, 2018

Note: Coloured columns show Member States' performance in 2017. The horizontal hyphens show performance in 2016 and the grey columns show Member States' performance in 2010 relative to the European Union in 2010.

Based on this, the Member States could be divided into four performance groups:

1. The Innovation Leaders: who perform well - above the European Union average (more than $20 \%$ );

2. The Strong Innovators: Innovators who perform above or close to the European Union average ( between $90 \%$ and $120 \%$ );

3. The Moderate Innovators: Innovators who perform below the European Union average ( between $50 \%$ and $90 \%$ );

4. The Modest Innovators: who perform well - below the European Union average ( below $50 \%$ ).

It follows that the performance groups, as shown in Figure 3.2 below, tend to be geographically concentrated. 
Figure 7 Fenoranhy of the Furnnean innovation nerformance

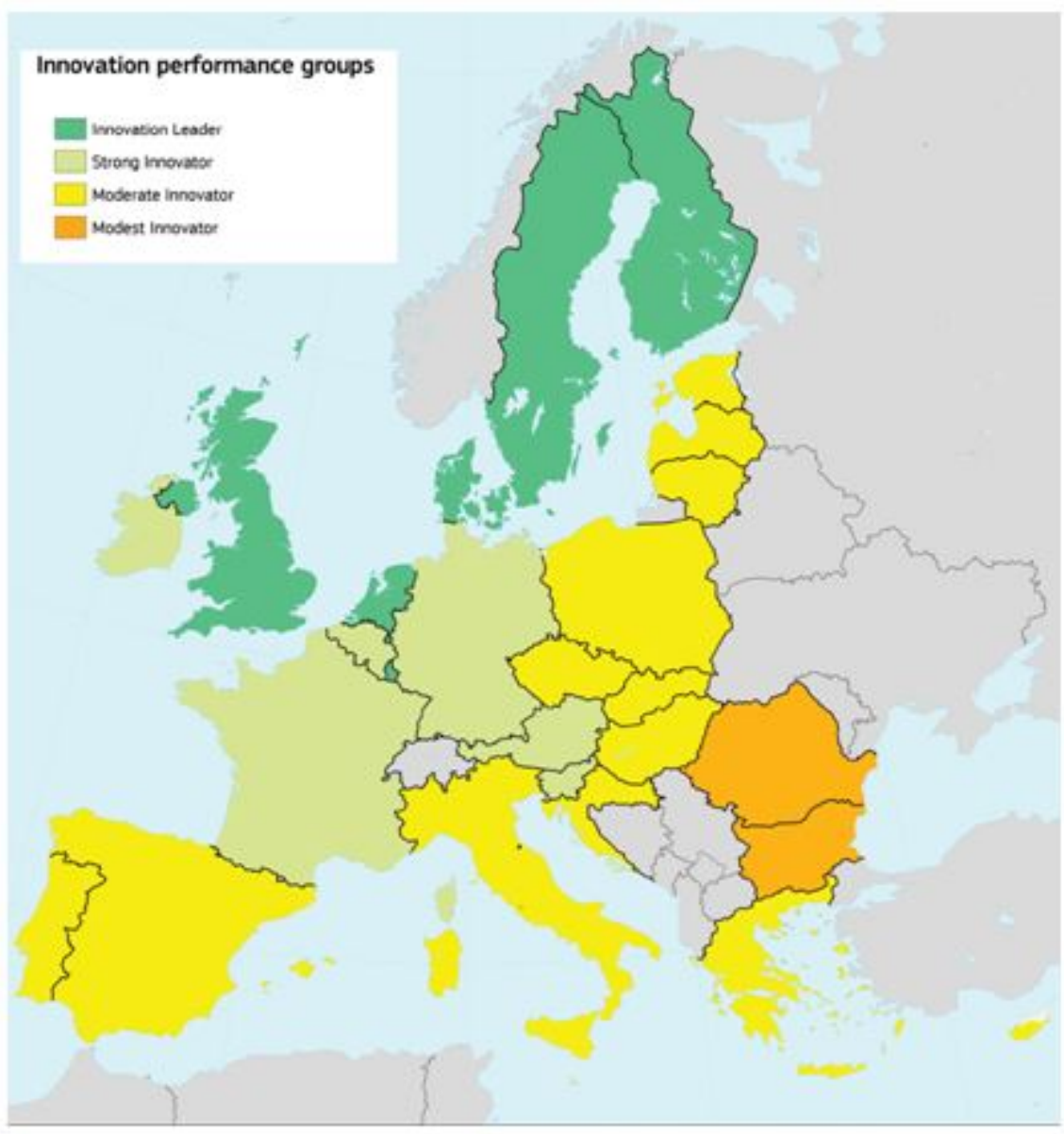

Source: European Innovation Scoreboard, 2018

As it is possible to stress out from the figure, the average European Member States' performance decrease with the increases of the geographical distance from the Innovation Leaders.Analyzing the past performances, it is possible to underline that less innovative countries tend to improve their performance faster than the level of the other countries; but now the changing in the performance is, generally, not related to the level of performance because the correlation coefficient between the change and the level in 2010 and 2017 is not statistically significant.

Figure 3. Chanoe in the innovation index hetween 2010 and 2017

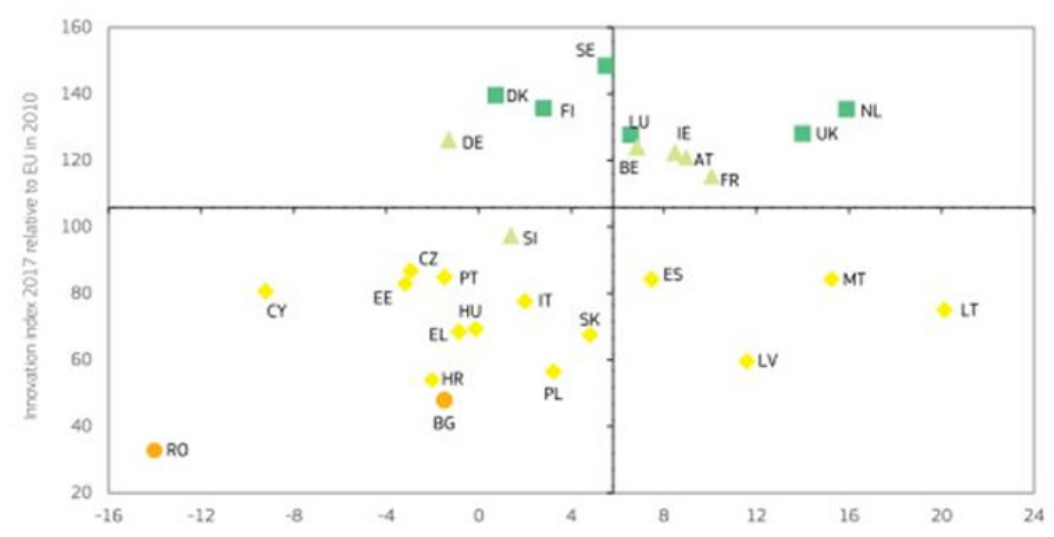

Source: European Innovation Scoreboard, 2018 
As it is possible to see from the above Figure 3.3, between 2010 and 2017, there is no convergence in the innovation performance between the Member States who performed at a lower level in 2010 and those performed at higher levels in 2017. It follows a detailed description of the performance evolution related to the four innovators' groups. Fo the Innovation Leaders group, as it is possible to stress out from Figure 3.4 below, the performance improved in 2013 followed by a decline in 2014.

Figure 4. Performance of Innnvation I eaders

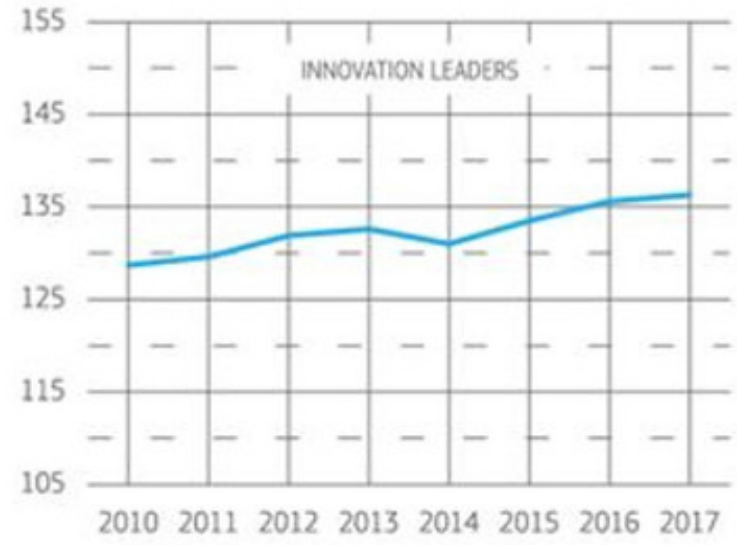

Source: European Innovation Scoreboard, 2018

Note: this graph shows the average performance of the Innovation Leaders, calculated as the unweighted average of the respective Member States

Also, the performance of improved again from 2015 to 2017, where they reach the peak level, as it is possible to see from the figure above.

Figure 5. Performance of Innovation I eaderc

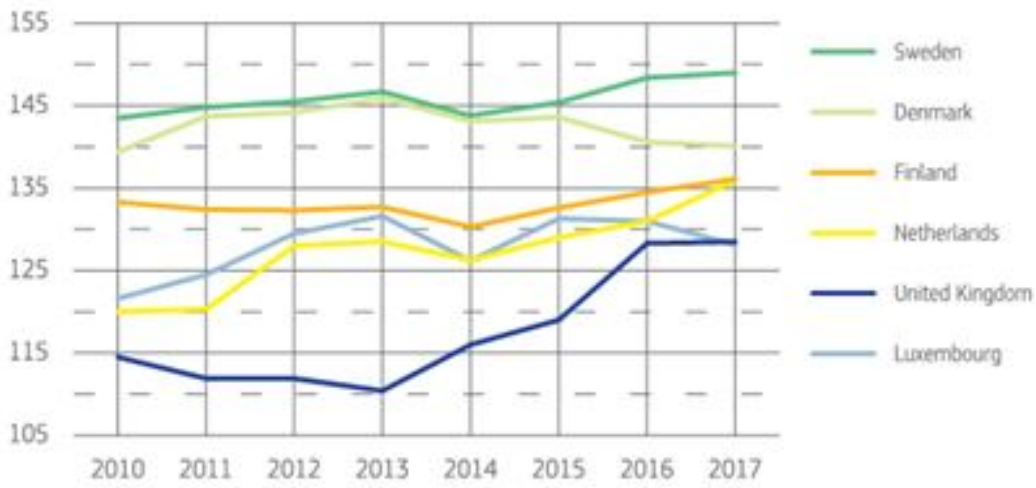

Source: European Innovation Scoreboard, 2018

In particular, as it is possible to see from the above Figure 3.5:

- The Netherland and the United Kingdom improved the most their performances, more than ten percentage points;

- $\quad$ Sweden and Luxembourg increased their performances but at a lower rate, $5 \%$ and $7 \%$ percentage points respectively;

- $\quad$ Finland improved by almost 3 percentage points and Denmark by less than 1 percentage points.

Carrying on, the Strong Innovators, as shown in Figure 3.6 below, performances remained stable until 2014, and after improved annually, average performed 5.7 percentage points compared to 2010. 
Figure 6. Performance of Strono Innnvatore

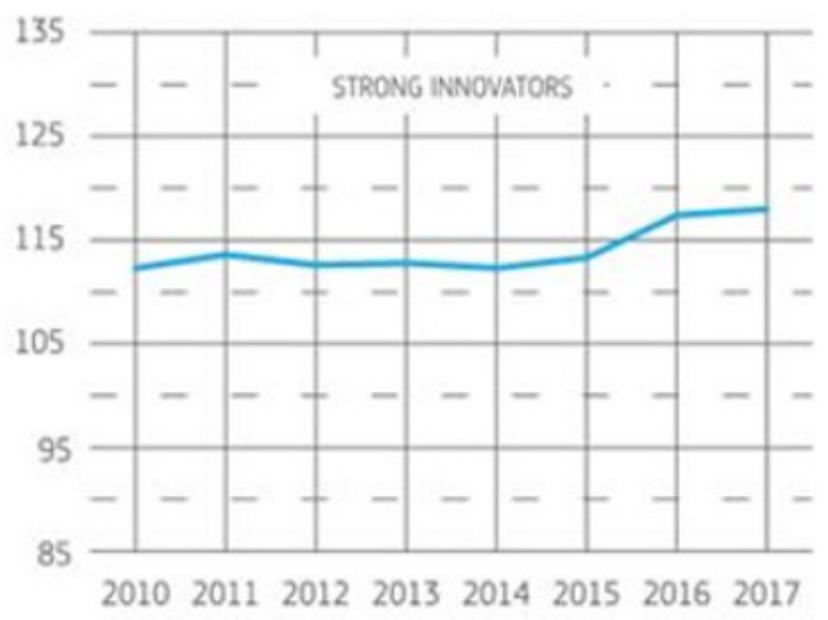

Source: European Innovation Scoreboard, 2018

Note: this graph shows the average performance of the Strong Innovators, calculated as the unweighted average of the respective Member States

Making a comparison between the previous figure and the Figure 3.7, there is a performance gap to form the Innovator Leaders which slightly increased between 2010 and 2017; and, at the same time, the graph's performance has improved for all the group members, except for Germany.

Figure 7. Performance of Strono Innovatore

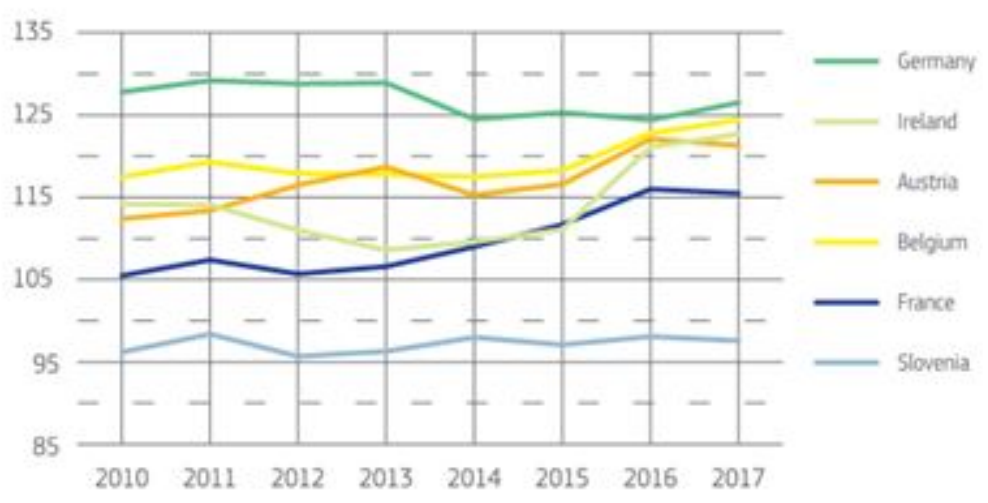

Source: European Innovation Scoreboard, 2018

More profoundly, as noted in the above Figure 3.7:

- France presents the most significant increase, 10.1 percentage points due to the substantial increase between 2014 and 2016;

- In Austria the performance level also increased sharply, 9.0 percentage points due to the steady increase in 2016;

- In Ireland, the performance level increased in 2016 leading to an overall increase of 8.6 percentage points;

- For Belgium, the performance level increased by 6.8 percentage points due to the annual performance increment since 2014 and the consequent increase in 2016. 
For the Moderate Innovators, the performance has been increased in cyclical trends with performance increment during odd-numbered years and, at the same time, performance decreased in even-numbered years, as it is possible to see from the Figure 3.8 below.

Figure 8. Performance of Mnderate Innovatore

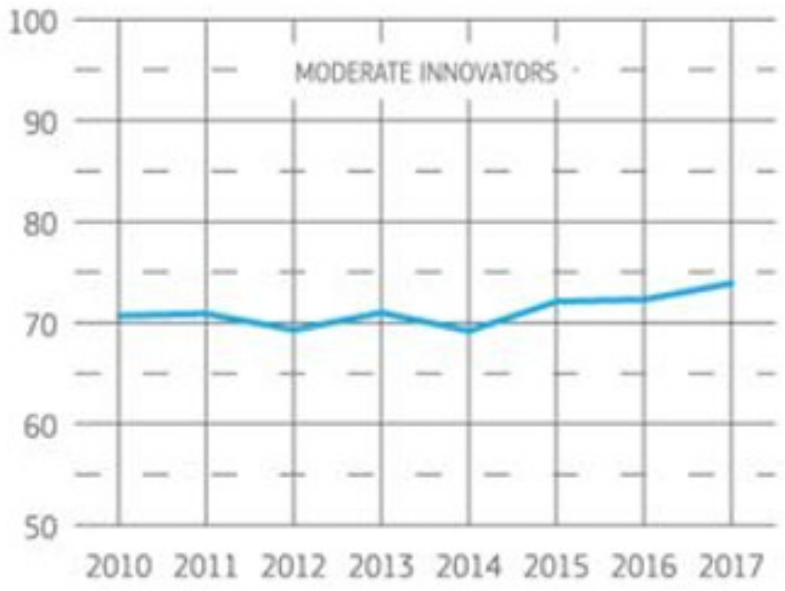

Source: European Innovation Scoreboard, 2018

Note: this graph shows the average performance of the Moderate Innovators, calculated as the unweighted average of the respective Member States

Compared with the Strong Innovators, the performance gap did not change between 2010 and 2017. As shown in Figure 3.9 below, for six Moderate Innovators the performance has increased.

Figure 9 Performance of Moderate Innovatore

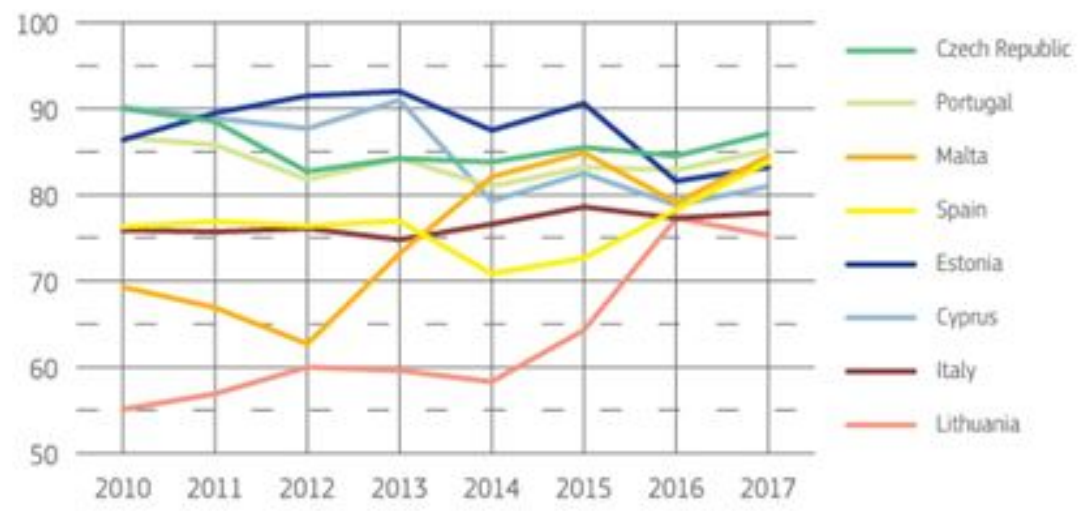

Source: European Innovation Scoreboard, 2018

Focusing the attention on Italy, it is possible to stress out that the Italian performance increased by 2.0 percentage points, with annual performance increment in 2012, 2015 and 2017. It follows that, compared to the European Union in 2010, the Italian performance has increased (Figure 3.10 below). 
Figure 10. Italian nerformance

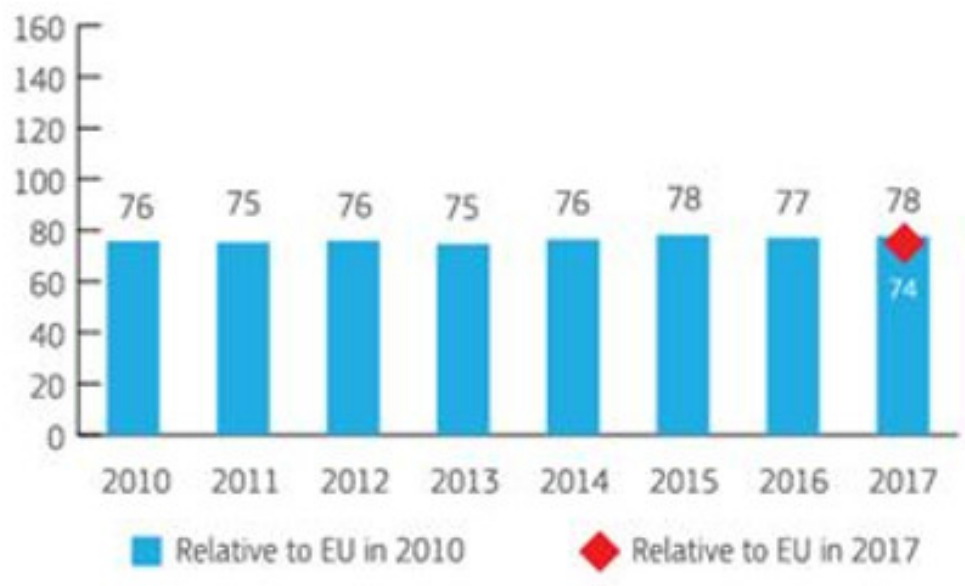

Source: European Innovation Scoreboard, 2018

In particular, as it is possible to stress out from the following Table 3.1, innovators and intellectual assets are the most critical and strategic innovation forces. Instead, the human resources and Finance are the weakest ones. Following from the previous table and

Table 1: Italian performance by a group of indicators

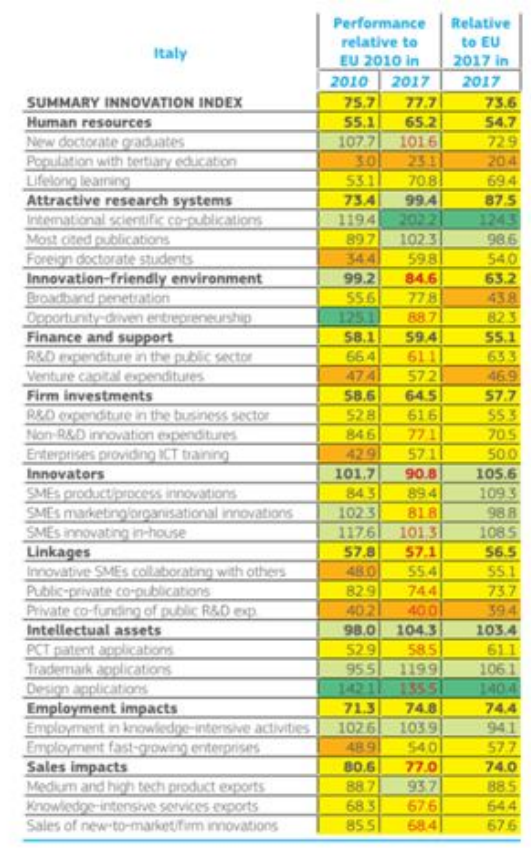

Source: European Innovation Scoreboard, 2018.

The dark green cells represent the normalized performance above the $120 \%$ of European Union. The light grey represent the normalized performance between $90 \%$ and $120 \%$ of European Union. The yellow represent the normalized performance between $90 \%$ and $50 \%$ of European Union. Data in red underline a performance decline compared to 2010.

figure, the existence of structural differences with the European Union as stresses out from the Table 3.2 below.

Coming back to the explanation of the European innovation context, for seven of Moderate Innovators, instead, performance has declined:

- $\quad$ For Hungary, performance decline is marginal, $0,1 \%$ point, and the performance has been increasing annually since 2013; 
Table 2: Italian performance compared to the European ones

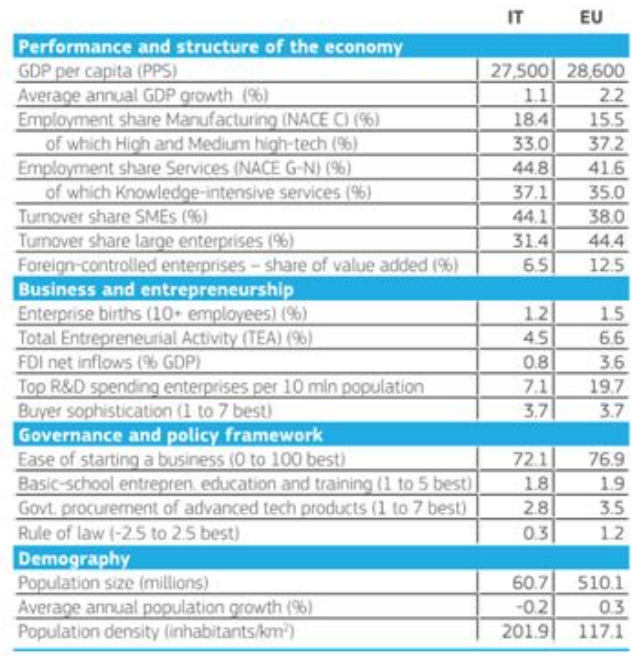

Source: European Innovation Scoreboard, 2018.

- $\quad$ For Croatia, the performance decline is by 2,0 percentage points with a steady decline in 2012 and 2014 ( not adequately compensated by increasing performance between 2015 and 2017);

- $\quad$ For Greece, the performance decline is 0,9\% point, resulting from a robust decline in 2014.

For the Modest Innovators, performance declined between 2010 and 2017, as it is possible to see from the following Figure 3.11 and Figure 3.12. This leads to a widening of the performance gap to the Moderate Innovators.

Figure 11. Italian nerformance

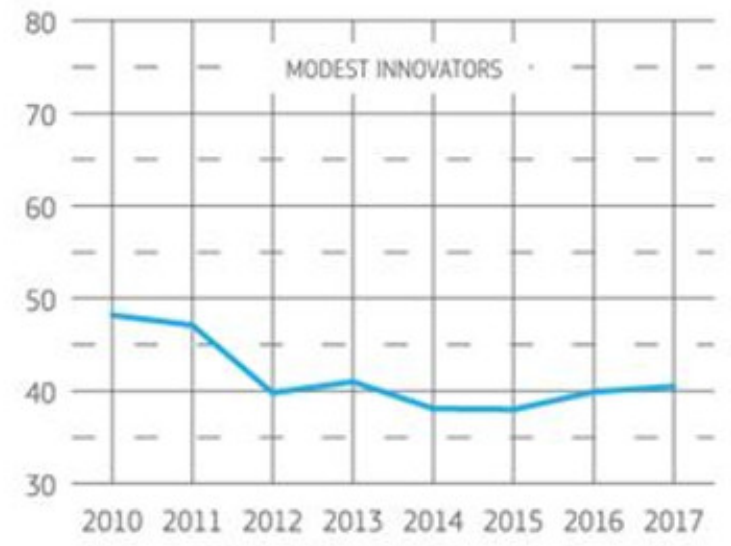

Source: European Innovation Scoreboard, 2018

Note: this graph shows the average performance of the Modest Innovators, calculated as the unweighted average of the respective Member States 
Figure 12. Performance of Modest Innovators

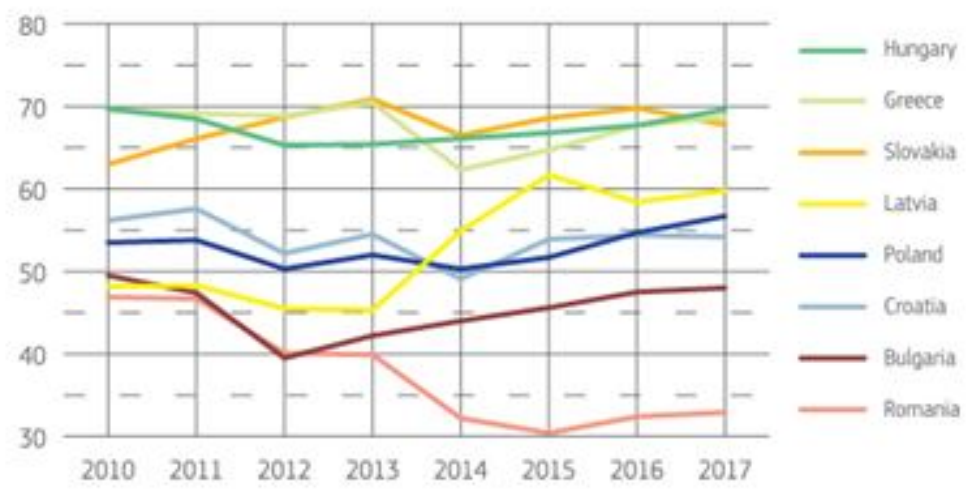

Source: European Innovation Scoreboard, 2018

In particular:

- For Bulgaria, performance in 2017 is still below the 2016's performance level;

- Romania, performance has declined sharply by 14.0 percentage points but, after five years of declining, performance increased again in 2016 and 2017.

All the previous consideration derived from an overall increment of the European Union Innovation System's performance by 5.8 percentage points between 2010 and 2017. As it is possible to figure out from the following Figure 3.13. 
Figure 13. Furnnean I Inion nerformance from 2010 to 2017 hv indicator and dimencion

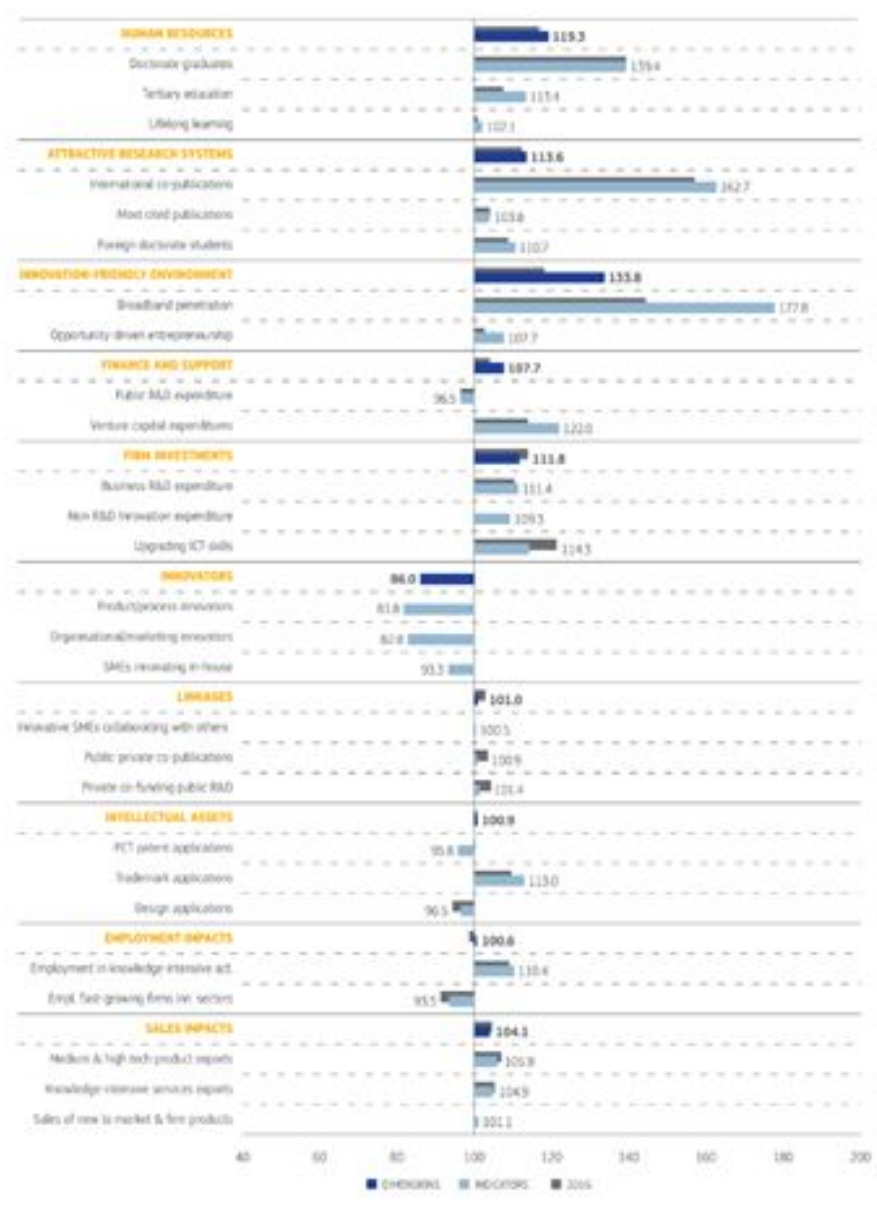

Source: European Innovation Scoreboard, 2018

Performance has improved most, by 33.8 percentage points, in Innovation - friendly environment, especially in Broadband penetration. Performance, instead, has not changed for Linkages, Employment impacts,where an increase in Employment in knowledgeintensive activities has been offset by a decline in Employment in fast-growing firms in innovative sectors. Now, we have seen what happened at national/country level but what is it possible to say about the regional innovation level?

As region are becoming essential engines of economic development, innovation performance deserves particular attention at the regional level ${ }^{10}$ and, as affirmed during all the present research work:

- Innovation is not uniformly distributed across regions;

- Innovation tends to be spatially concentrated over time;

- Even regions with similar innovation capacity have different economic growth patterns.

Also, differences in economic structures, like differences in the share of GDP, could explain why regions might perform better or worse on indicators, like R \& D Expenditure and Innovative Enterprises. As a consequence, regional profiles might be necessary for explaining differences in R \& D spending and innovation activities: densely populated areas also more likely to be more innovative for several reasons, like for example: 
- $\quad$ People and enterprises being at closer distance permit to the knowledge to flow more easily;

- In urbanised areas, there is a tendency to have the concentration of governments and educational services: better training opportunities and highly educated people's employment rate above - average shares.

So, like the European Innovation Scoreboard, based on the Regional Innovation Index ${ }^{11}$, regions could be classified into four different performance group:

1. Regional Innovation Leaders: who include 53 regions with performance more than 20\% above the European Union average;

2. Strong Innovators: who include 60 regions with performance between $90 \%$ and $120 \%$ of the European Union average;

3. Regional Moderate Innovators : who includes 65 regions with performance between $50 \%$ and $90 \%$ of the European Union average;

4. Regional Modest Innovators: Innovators who include 22 regions with performance below $50 \%$ of the European Union average.

As shown in the radar graph below (Figure 3.14), the most innovative regions, on average, perform best on most indicators (where in the graph the line for the Regional Modest Innovators is primarily embedded within the line of the Regional Strong Innovators.

11 This index summarizes the performance of 27 indicators divided in four main types: Framework conditions, Investments, Innovation activities and Impacts; and ten innovation dimensions. This index is limited due to the availability of regional innovation data for 18 of 27 indicators used into the European Innovation Scoreboard: for several indicators slightly different definition have been applied. 
Fio11re 14 Indicators senre hv reoinnal nerformance orninc

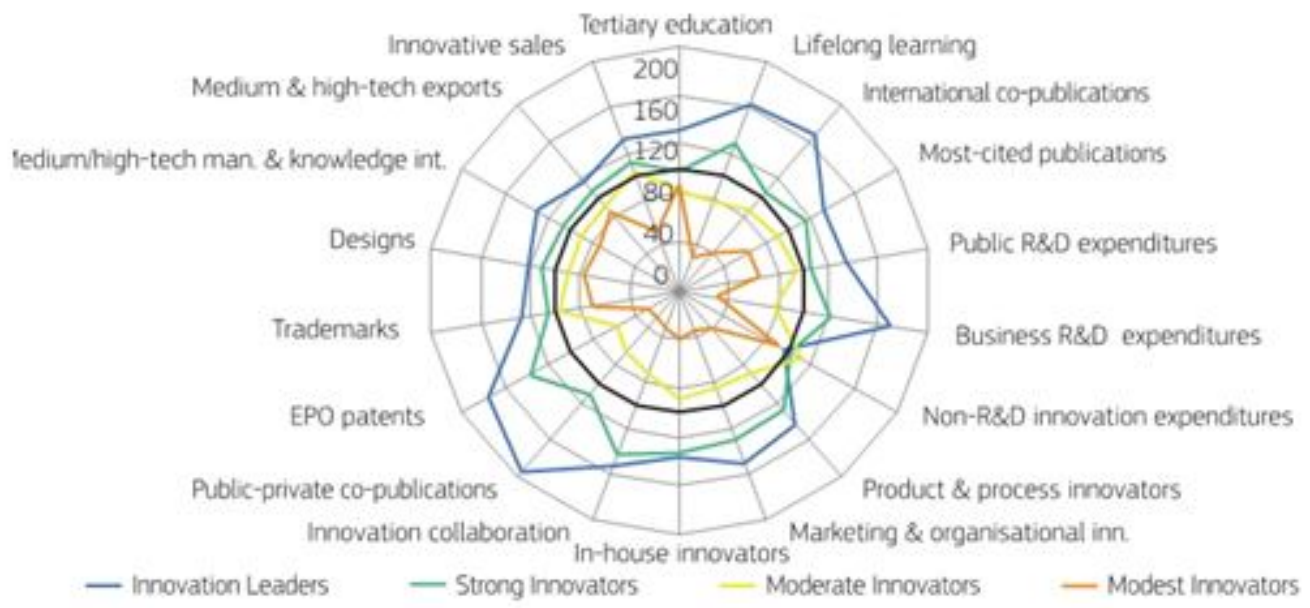

Source: Regional Innovation Scoreboard, 2018

In particular, the line of the Regional Innovation Leadershas shown that they have the highest performance on all indicators (except for Non-R \& D Innovation Expenditures, where, instead, the Regional Moderate Innovators have the highest average performance level).

Despite the variation in regional performance, regional performance groups mostly match the similar European Innovation Scoreboard country performance, groups.

Fioure 15 Reoinnal nerformance ornınc ve F.11rnnean innovation nerformance ornı1nc
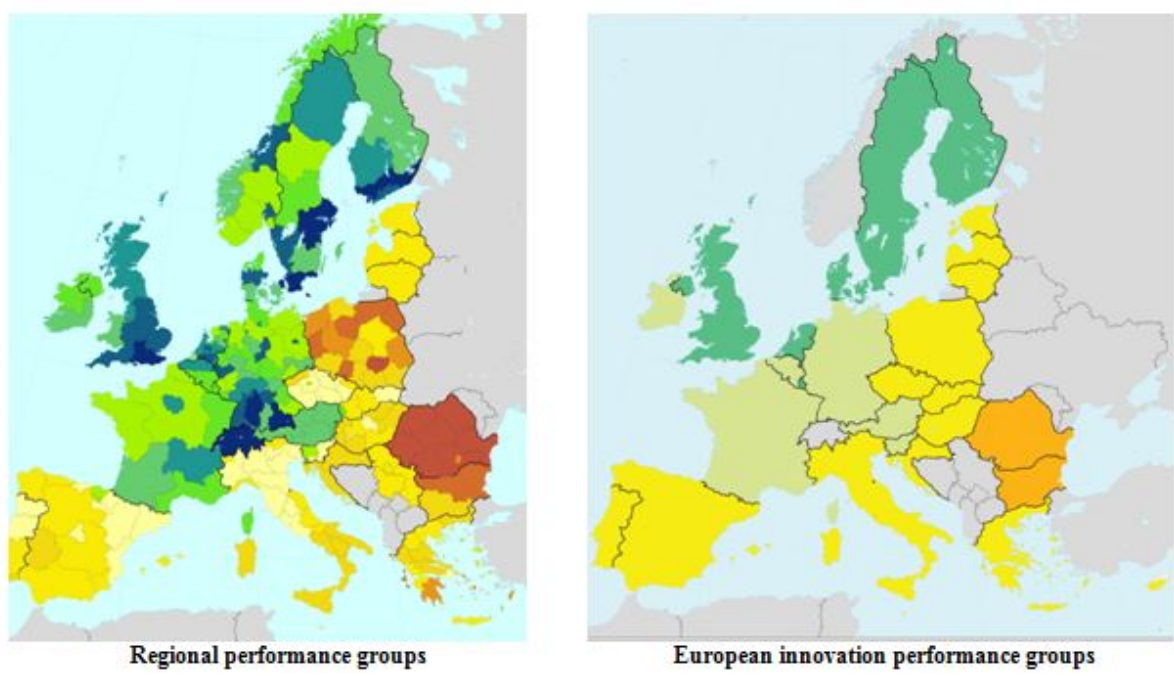

Source: Author's elaboration

As shown in the above Figure 3.15 :

- $\quad$ Most of the Regional Innovation Leaders are located in countries previously identified as Innovation Leaders ;

- Most of the Regional Innovation Strong Innovators and Moderate Innovators are located in countries previously identified as Strong Innovators: and Moderate Innovators respectively;

- $\quad$ All the Regional Moderate Innovators who includes 65 regions with performance between $50 \%$ and $90 \%$ of the European Union average; 
1. Regional Modest Innovators are located in countries previously identified as Modest Innovators.

As a consequence, the regional "poker of excellence" could be identified in some Moderate Innovator countries like Praha (Prague) in the Czech Republic, Bratislavsky in Slovakia and Paìs Vasco (Basque Country) in Spain; when some regions in Innovation Leaders and Strong Innovator countries lag, like Friesland in The Netherland.

Following, introducing and using three sub-groups ${ }^{12}$ within each performance group, at the regional level, as shown in Figure 3.16 below.

Figure 16. Regional nerformance ornıns

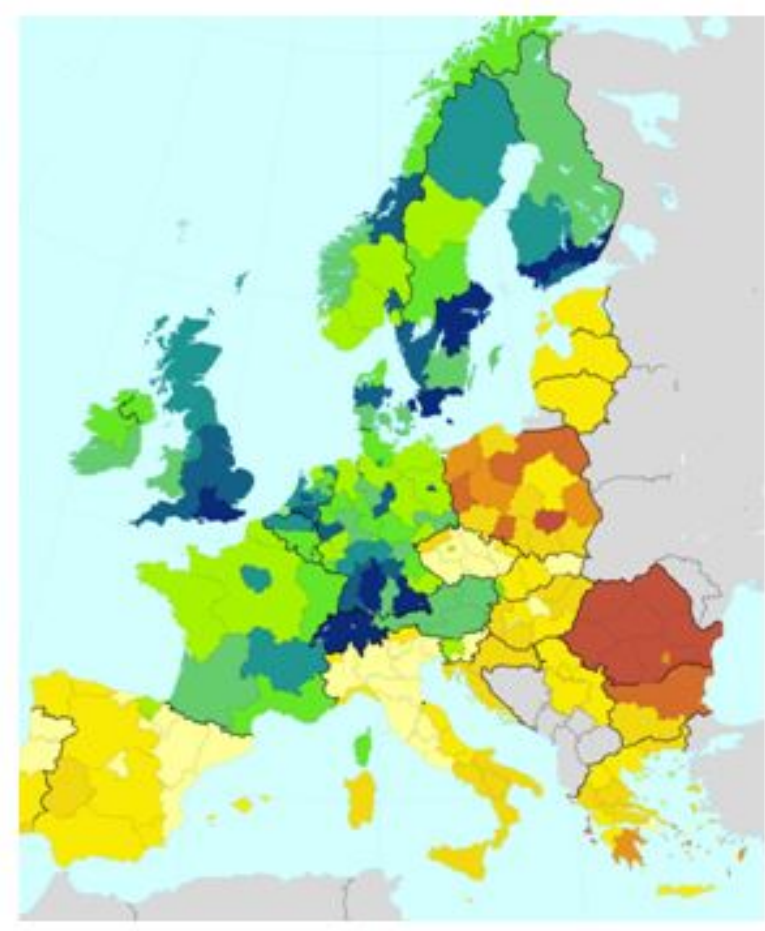

Source:Regional Innovation Scoreboard, 2018

From the previous figure, it is possible to identify two key evidence:

- $\quad$ - Most of the Innovation Leaders and Strong Innovators are locatedin the former European Union 15 Countries in North-West Europe; ;

- Most of the Moderate Innovators and Moderate Innovators are located in the newer Members States and former European Union 15 Countries in the South of Europe.

Also, in this framework, focusing our attention on Italian performance score, Italy is identified as Moderate Innovators.

12 It is necessary to stress out, even if here it is not reported, that there are the most divergence in regional innovation systems' performance of with countries and capital regions (including the largest metropolitan capital areas) tending to perform better than other regions in the same countries. 
Table 3: Italian regional performance

\begin{tabular}{|c|c|c|c|c|c|}
\hline NuTs & Regon & Ail 2017 & Pand & Grois & change \\
\hline ITCl & Piemonte & 79.8 & 125 & Moderate + & 0.6 \\
\hline ITC2 & Valie dAosta/ Vallee dAoste & 590 & 168 & Moderate & -1.3 \\
\hline $1 \mathrm{TC3}$ & Liquna & 69.6 & 145 & Moderate & 4.1 \\
\hline $\mathrm{ITC} 4$ & Lombairdia & 796 & 127 & Moderate + & -0.8 \\
\hline ITH1 & $\begin{array}{l}\text { Provincia Autonoma Bolzanol } \\
\text { Boren }\end{array}$ & 69.4 & 147 & Moderate & 2.6 \\
\hline ITH2 & Provincia Autonoma Trento & 78.4 & 129 & Moderate + & 13 \\
\hline ITH3 & Veneto & 79.4 & 128 & Moderate + & 0.2 \\
\hline ITH4 & Friuli-Venezia Giulia & 878 & 117 & Moderate + & 3.6 \\
\hline ITHS & Emilia-Romagna & 799 & 124 & Moderate * & -16 \\
\hline ITII & Toscana & 755 & 133 & Moderate + & 6.6 \\
\hline $1 \mathrm{TI2}$ & Umbira & 74.3 & 137 & Moderate + & 5.7 \\
\hline ITI3 & Marche & 69.4 & 148 & Moderate & 0.8 \\
\hline 1714 & Lazio & 73.6 & 138 & Moderate * & -2.9 \\
\hline ITF1 & Abruzzo & 64.5 & 158 & Moderate & 3.2 \\
\hline ITF2 & Molise & 61.0 & 164 & Moderate & 4.9 \\
\hline ITF3 & Camparea & 57.8 & 173 & Moderate - & -1.5 \\
\hline ITF4 & Puglia & 58.5 & 170 & Moderate - & -0.6 \\
\hline ITFS & Basulicata & 579 & 172 & Moderate - & 0.0 \\
\hline ITFG & Calabna & 578 & 174 & Moderate - & 7.7 \\
\hline ITG1 & Sicila & 51.3 & 194 & Moderate - & -1.9 \\
\hline ITG2 & Sardegna & 52.4 & 190 & Moderate - & -1.1 \\
\hline
\end{tabular}

Source:Regional Innovation Scoreboard, 2018

Table shows the rank performance in 2017 across all regions, the Group column shows the respective performance group, the Change column shows the performance change over time calculated as the difference between the performance in 2017 (RII 2017) relative to that of the EU in 2011 and performance in 2011 (RII 2011) relative to that of the EU in 2011.

As it is possible to see from the previous Table 3.3, regional performance differences are high within the Italian context, with the best performing region, Friuli - Venezia Giulia, performing $70 \%$ higher than the lowest performing region, Sicilia. Comparing the North and the South of Italy, it is possible to affirm that the innovation performance is higher in more northern regions compared to the southern ones: for 12 regions, performance has improved, in particular for Calabria $(+7.7 \%)$ and Toscana $(+6,6 \%)$ and 8 of them, performance has declined.

In conclusion of this section, it is possible to explain the performance's changing over time and making a comparison with the Regional Competitiveness Index. Regarding the first aspect, the performance of the regional innovation systems changes over time. In particular, it is possible to notice the presence of divergence process in the regional performance with increasing performance differences between regions: the spread in the regional innovation performance, measured by the sigma-convergence, has increased over time despite the decline in the most recent period. Geographically speaking, this performance decline is present in the peripheral regions in the South and East of Europe (Finland, Italy and Romania) but also in Central Europe, in particular in Germany. Instead, performance increase in all regions in Austria, Belgium, France, The Netherlands, Norway, Slovakia, Ireland and United Kingdom; and in most of 50\% regions in Greece, Italy, Poland and Sweden. Regarding the second aspect, according to Figure 3.17 below, Regional Innovation Index and the Regional Competitiveness Index are strongly and positively related (0.844). 
Fiowre 17. Sratter nlet hetween RII 2017 and RCI 2016 and Innnvation sıhindex
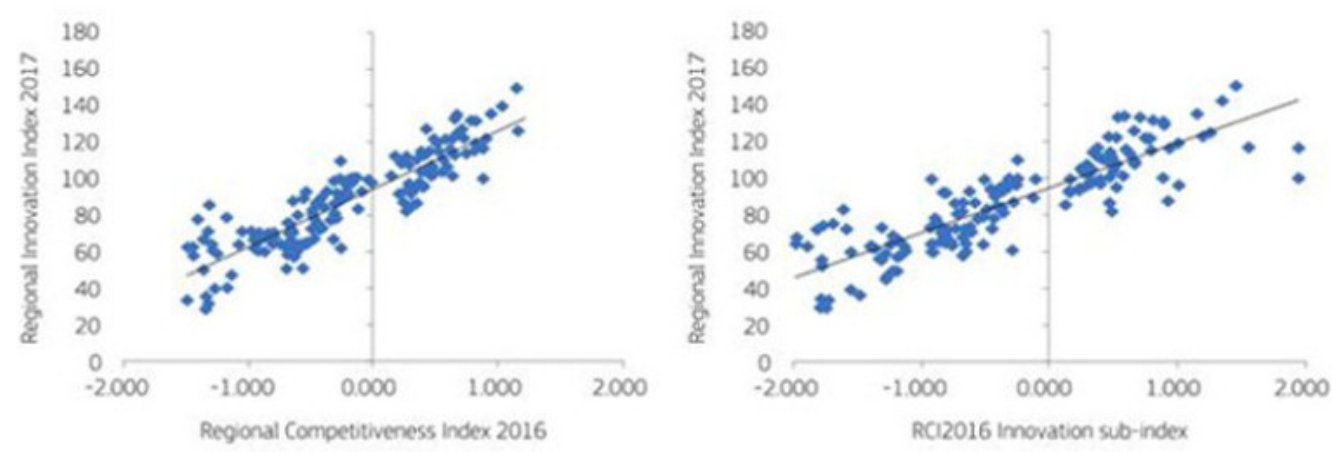

Source:Regional Innovation Scoreboard, 2018

As it is possible to see from the previous figure, regions which are more innovative, are also more competitive, stressing the needs for policy to stimulate and improve performance and, at the same time, it is not possible to get any conclusion on the direction of a possible causality relation, like being more innovative triggers increased competitive performance or if being more competitive triggers in innovation performance

\subsection{Methodology}

As said in the introduction of this chapter, in the first part of this section is introduced the two statistical tools used for the empirical analysis: the Self - Organizing Maps (SOMs hereafter) and the La Fuente and Vives (1995) multivariate regression approach. The Self - Organizing Maps is a topographic map which represents an essential instrument for the visualisation and exploration of the high-dimensional data. In this sense, the Self - Organizing Maps ${ }^{13}$ is one of the most-used algorithm that lead to a wide range of applications: the most important is the clustering, that represents the direct consequence of the data visualization and the exploration capabilities of the topographic map: This approach will be used in this empirical part of the present research work. It allows to analyze the performance of the Italian regions from a pre-crisis scenario, 2005- 2010, to a post-crisis scenario, 2011 - 2016, providing a short - term evaluation of the dataset used. The multivariate regression model, instead, is configured as two-stage product process model and it could be modelled using a nested regional production function. In the second part of this section, it will introduce the database used for the analysis. are gradually decreased over time. When the neighbourhood range vanishes, the previous learning rule goes back to standard unsupervised competitive learning. In conclusion, with regards of the effect of the neighbourhood function, the SOM algorithm tends to under sample high probability regions and oversample the probability: the visual effect is the cluster's separability when the cluster overlap.

\subsubsection{The neuronal tool: the Self - Organizing Map}

In this framework, neurons become "selectively tuned" to various input patterns ( stimuli) or classes of input patterns during the course of the competitive learning stage. As a consequence, the location of the neurons become ordered and a meaningful "coordinate system" for the "input feature" is created on the lattice.

The SOM algorithm distinguishes two stages, the competitive and the cooperative ones. In the first stage, the best-matching neurons are selected, for example, the "winner", as happens in the Kohonen Network appraoch; and in the second stage, the weights of the

13 In this research work, it is used a particular type of Self - Organizing Maps known as a Kohonen Network.This type of Self - Organizing Maps has a feed-forward structure with a single computational layer arrayed in rows and columns, where each neuron is fully connected to all the source needs in the input layer. 
winner are adapted as well as those of its immediate lattice ${ }^{14}$ neighbours.

Competitive stage: for each input, it is selected the neuron with the smallest Euclidean distance, called the "winner", according the equation 3.1 :

$$
i^{*}=\operatorname{argmin}_{i}\left\|w_{i}-v\right\|
$$

By the minimum Euclidean distance role, it is obtained a Voronoi tessellation of the input space (the grey shaded area in the figure 3.18).

Figure 18. Definition of c11antication reoinn in the Self-Croanizino Man (SOM

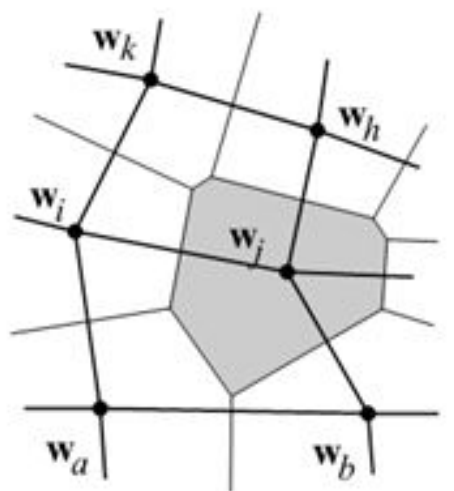

Source: Van Hulle,(2012)

In this figure, it is represented the Portion of a lattice (thick lines) plotted in terms of the weight vectors of neurons $a, . ., k$, in two in the two-dimensional input space i.e. $w a, \ldots, w k$.

As it is possible to see from the previous figure, to each neuron correspond a region in the input space in which the boundaries are perpendicular bisector planes of lines of joining pairs of weight vectors ${ }^{15}$.

Cooperative stage: In this stage is crucial the formation of the topographically-ordered maps in which the neuron weights are not modified independently of each other. During the learning process, not only the weight - vector of the winning neuron is updated but also those of the lattice neighbours. This is achieved with the neighbourhood function, centred at the winning neuron and decrease $s$ with the lattice distance of the winning neuron; and the weight update rule in incremental mode ${ }^{16}$ is:

$$
\Delta w_{i}=\eta \Lambda\left(i, i^{*}, \delta_{\Lambda}(r)\right)\left(v-w_{i}\right) \forall i \in A
$$

where $\Lambda$ is the neighbourhood function. This function, being mostly Gaussian, the previous equation 3.2 could be rewritten in the following way, if we suppose that the neighborhood function follows a Gaussian distribution:

$$
\Lambda\left(i^{*}, i\right)=\exp \left(-\frac{\left\|r_{i}-r_{i}^{*}\right\|}{2 \delta_{\Lambda}^{2}}\right)
$$

An example of the effect of the neighbourhood function could be seen in Figure 3.19 below.

14 The lattice is an undirected graph in which every non- border vartex has the same fixed number of incident edges.

15 The neuron weights are connected by straight lines indicating which neurons are nearest neighbours in the lattice.

16 In this way, the weights are updated and generated and input vector each time, contrasting with the batch mode where the weights are only updated at the end of the full training set. 
Figure 19. The effect of the noiohhnurhond function in the $\mathrm{S} \cap \mathrm{M}$ alonrithm

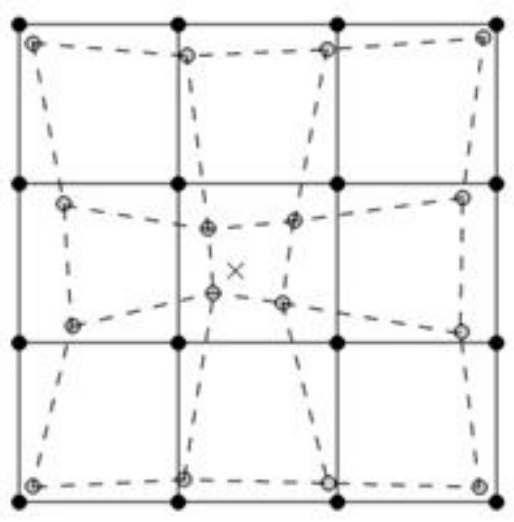

Source: Van Hulle,(2012)

Starting from a perfect arrangement of the weights of a square lattice (full lines), the weights nearest to the current input (indicated with the cross) receive the largest updates, those further away smaller updates, resulting in the updated lattice (dashed lines).

As it is possible to see from the previous figure and the functioning of the neighborhood function, the parameter $\delta_{\Lambda}$ and the learning rate $\eta$ are gradually decreased over time. When the neighbourhood range vanishes, the previous learning rule goes back to standard unsupervised competitive learning. In conclusion, with regards of the effect of the neighbourhood function, the SOM algorithm tends to under sample high probability regions and oversample the probability: the visual effect is the cluster's separability when the cluster overlap.

In this effect, according to Van Hulle (2012), the cluster boundary will be more difficult to delineate in the overlap region instead of mapping which has a linear weight distribution.

Under the application point of view, the geographical map generated by the SOM algorithm is closely understandable: clustering is defined as the partitioning of the data set into subsets of "similar" data without using a prior knowledge about the subsets. In this type of application, clusters and their boundaries were defined by the user and, for visualise them, it is necessary an additional technique: the computation of the mean of the Euclidean distance between neuron's weight vector and the weight vectors of its nearest neighbours in the lattice. When the maximum and the minimum of the distance if found for all neurons, it is used for scaling these distances between 0 and 1 ; then the lattice becomes a "grayscale" image. This lattice is called the U-Matrix.

3.2.2. The multivariate regression model tool: the two-stage production process model

Following the De La Fuente and Vives (1995) approach, the production of intermediate goods requires only private inputs of capital and labour whose productivity depends on the average stock of human capital per worker in the region. The output level of intermediate goods, $Y_{i t}$, in region can be described by the Cobb-Douglas production function:

$$
Y_{i} \equiv B_{i} K_{i}^{a} L_{i}^{1-a} H^{b}
$$

where $B$ is the total factor productivity, $K$ is the firm's stock of capital, $L$ is the employment, $H$ is the average human capital per worker's stock in a region $i$, and $a$ ,$b$ are constants parameters. The final output $X_{i}$, produced in the region $i$, depends positively . However, unlike De La Fuente and Vives (1995) approach, the volume of output depends, positively, on the density of the telecommunication network, $T$ and $P$ respectively. At the aggregate level, it might be reasonable to assume that the regional 
final goods production function is characterized by the constant returns to scale property. Thus, if the intermediate goods input, the the digital and social capital infrastructures are increased simultaneously by the same percent in the final output. Consequently, the second stage production function can be written as:

$$
X_{i} \equiv Y_{i}^{c} P_{i}^{y} T_{i}^{\tau} H_{i}^{1-c-y-\tau}
$$

Where $c+y+\tau>1, c>0, y>0$ and $\tau>0$. Putting 3.4 in 3.5, allows to obtain the reduced form regional production function capturing specifically the impact of the on the level digital and social capital infrastructures of aggregate regional output:

$$
X_{I}=B_{i}^{c} K_{i}^{\alpha c} L_{i}^{(1-\alpha) c} H_{i}^{\beta} P_{i}^{y} T_{i}^{\tau}
$$

By defining $\alpha=a c, \beta=(1-a) c, \alpha+\beta=c, A \equiv B$ and $v=b c$, one obtains a reduced form of the regional production function (3.4) that describes the impact of intermediate goods and digital and social capital infrastructures on the level of regional output of final goods:

$$
Y_{i} \equiv A_{i} K_{i}^{\alpha} L_{i}^{\beta} H_{i}^{v} P_{i}^{y} T^{\tau} i
$$

Like in the traditional neoclassical model, it is assumed that under perfect competition, capital is perfectly between different regions and moves instantaneously across the country in response to even the smallest differences in its marginal product The capital flows across regions until its marginal product is equalized at all locations whereas digital and social capital infrastructures, labour and human capital are fixed factors whose supplies are predetermined exogenously in a region and do not depend on differences in their marginal product across regions.

In equilibrium, the stock of capital in the region $i$ is a function of the national capital stock and the regional endowments of immobile factors:

$$
\begin{aligned}
\ln Q_{i}= & \ln \Theta+\left(\frac{1}{1-\alpha}\right) \ln A_{i}+\left(\frac{\beta-1}{1-\alpha}\right) \ln L_{i}+\left(\frac{V}{1-\alpha}\right) \ln H_{i}+\left(\frac{y}{1-\alpha}\right) \ln P_{i}+ \\
& +\left(\frac{\tau}{1-\alpha}\right) \ln T_{i}+\left(\frac{1-\alpha-\beta-y-\tau}{1-\alpha}\right) \ln S i
\end{aligned}
$$

The reduced form per-worker regional production function (3.5) allows to identify the relationship between the level of regional income per worker and the two types of policy tools subject of analysis.

\subsubsection{The database used for the analysis}

In this empirical subsection, it is introduced the dataset used for the analysis for the periods 2005-2016. During the study, it is chosen the variables from Rapporto Noi Italia 2018 developed by the Italian National Institute of Statistics (ISTAT), represented in the following Table 3.5, because it was necessary to cope with two main restrictions: the data availability by Italian regions during the chosen period and the choice of aggregate indicators of social capital. Regarding the first restriction, the division into two subs periods, 2005- 2010 and 2011 - 2016, allows the evaluating of the dataset from a pre-crisis to a post-crisis scenario. Regarding the second, distinguishing among different social capital conceptualisations might lead to ambiguities at the operational level because it could imply the selection of different research strategies ${ }^{17}$.

Following this approach, the choice of regional - level indicators derived from some empirical literature like Ahmed and Alzahrani (2017), Andriani and Karyampas (2009), Degli Antoni, G. (2006), Gaved and Anderson (2006), Rainie et al. (2006) and Putnam

17 During the present research work, social capital is considered to be an attribute of networks and regions. 
(2000). After choosing the variables, indicators are divided into three macro-categories linked to the Italian experience: Social and Human capital, ICT use and Innovation and Economy; as could be observed from Table 3.4 below.

Table 4: List of performance indicators from Noi Italia 2018 (years: 2005 - 2016).

\begin{tabular}{|c|c|}
\hline Function & Indicator \\
\hline Social and Human capital & $\begin{array}{c}\text { Government Expenditure for education } \\
\text { Tertiary education } \\
\text { Unpaid work for organisations } \\
\text { or volunteer groups } \\
\text { Satisfaction with friendly relations } \\
\text { Participation in lifelong learning } \\
\text { NEET } \\
\text { Satisfaction with family relations }\end{array}$ \\
\hline ICT use and innovation & $\begin{array}{c}\text { Business R\&D expenditure } \\
\text { Enterprises's website/homepage } \\
\text { Enterprises's e-commerce } \\
\text { R\&D Personnel } \\
\text { Households' broadband connection } \\
\text { Interaction with public authorities } \\
\text { Ordered/bought over the Internet } \\
\text { Science and Technology (S\&T) Graduates }\end{array}$ \\
\hline Economy & $\begin{array}{c}\text { GDP per capita } \\
\text { Total R\&D Expenditure } \\
\text { Employment rate }\end{array}$ \\
\hline
\end{tabular}

The first set of indicators considered by this research work concerns human and social capital. It has used for human capital proxies, variables related to the education field because, according to the Higher Education Modernisation Agenda, higher education, with its links with social capital, research and innovation, could play an critical role in personal development, providing highly qualified people and articulate citizens, necessary to create jobs and economic prosperity. Following this approach, the 'Final consumption expenditure by General Government on education and training (years 2005-2016 - as percentage of GDP)' (variable: Government Expenditure for education), the 'People aged 30-34 with tertiary education (years 2005-2017 - percentage values)' (variable: Tertiary education), the 'Percentage population aged 25-64 participating in lifelong learning (years 2005-2017 - percentage values)' (variables: Participation in lifelong learning), the 'Young people neither in employment nor in education or training (NEET) (years: 2005 - 2017 - percentage values)' (variable: NEET) are used as indicators for human capital. For the social capital proxies, instead, it has used variables linked to the functional/cognitive and relation social capital spheres.

As it has seen in the first part of Chapter 2 of this research work, the previous social capital dimensions are an essential framework where social capital could occur and grow: information and trust are vital for a network since they represent most of the network's 'intangible' resources, which help the society to achieve either economic and social outcomes (like well-being and higher employment rate) or intangible outcomes ( such as sense of social security).

Following this approach, the 'People aged 14 and over who during the last 12 months have carried out unpaid work for organizations or volunteer groups (years 2011-2016 percentage values)' (variable: Unpaid work for organizations or volunteer groups), the 'People aged 14 and over who have declare themselves very satisfied with the friendly relations (years: 2005 - 2013 - percentage values)' (variable: Satisfaction with friendly relations), the People aged 14 and over who have declared themselves very satisfied with the family relations (years: 2005 - 2013 - percentage values)' (variable: Satisfaction with family relations) are used as proxies for social capital. 
The second set of indicators used for the analysis is related to the use of ICT and Innovation. Regarding the ICT usage, Information and Communication Technologies (ICTs) impact on the communities in which we live and the way individuals, business and governments and civil society interact and develop. Regarding the Innovation, instead, it is a vital element for facilitating integration and scaling - up initiatives for the production and exploitation of knowledge. Following this approach, the 'Business R\& D Expenditure (years 2005-2015 - as percentage of GDP)' (variable: Business R\& D Expenditure), the 'Enterprises owing a website/homepage or at least one website (years 2005-2017 - percentage values)' (variable: Enterprises' website/homepage), the 'Enterprises with e-commerce activities (years 2005-2017 - percentage values)' (variables: Enterprises' e-commerce), the 'R \& D Personell (years: 2005 - 2017, per 1.000 inhabitants)' (varaible: R\& D Personell ), the 'Households that are connectable to the Internet over a broadband connection (years 2006-2017 - as percentage of households with the same characteristics)' (variable: Households's broadband connection), the 'People aged 14 and over who have interacted with public authorities in the last 12 months (years 2008-2016)' (variable: Interaction with public authorities), the 'People who have ordered/bought over the Internet between 3 months and a year ago (years 2005-2016 )' (variables: Ordered/Bought over the Internet), the 'Science and technology (S\& T) graduates (years: 2005 - 2017, per 1,000 nhabitants aged 20-29 years) ' (varaible: S\& T Graduates) are used as variables for ICT and Innovation indicators.

The last set of indicators refers to the economic performance of the Italian regions at an aggregate level. It has been used those types of variables with the aim to capture how networks, interactions and innovation are translated into economic assets and become economic capital., used to achieve their economic standings. Based on this the 'GDP per capita (years : 2005 - 2015, reference year 2010)' (variable: GDP per capita), the ' Total R \& D expenditure (years : 2005 - 2015, percentage of Gdp)' (variable: Total R \& D Expenditure) and the 'Employment rate (20-64 years) (years: 2005 - 2016, as percentage values)' (variable: Employment rate) are used as proxies for the economic performance level of the Italian regions.

\subsection{What it is happening in Italy: Is it possible the rising of the Smart Regions?}

It was used a SOM approach to provide a short-term evaluation of the possible future conditions for the rising of Smart Regions in the Italian context. It has chosen this tool for, at least, two reasons: first, instead of multidimensional scaling approach, its input observations are not categorised a priori and, as a consequence, the structure is unknown. The output network could be considered as a sort of statistical space or virtual topology in which the spatial configuration is closely linked to the statistical properties of the dataset. Secondly, this tool could show in an understandable way complex entities. This property is particularly crucial at a policy support level, where the understanding of the existence of possible mechanisms between the variables used is vital for appropriate decision-making. For studying the existence of this possible mechanism between variables, the analysis has been divided into three steps: in the first one, it has considered the studying of the percentage variations of the three macro-categories in which is divided the dataset used for the analysis; allowing to describe what is happening in Italy at a macro - level and under static perspectives. Following, in the second step, it has considered the evolution of the Italian regions from 2005 to 2016 through the use of the SOM algorithm. In conclusion, in the last step of the analysis, it has analysed in which way the social and digital infrastructure could influence the rising of the Smart Regions in the Italian context, more deeply through the use of the multivariate regression model based on the La Fuente and Vives (1995) approach; providing possible policies for future implementations.

Starting from the first step of the analysis, the following Tables; Table 3.5, Table 3.6 and Table 3.7; below; show, from the period 2005-2016, significant increments in all the 
macro-categories considered for the analysis.

Table 5: Variations of Human and Social capital indicators from 2005 to 2016.

\begin{tabular}{|c|c|c|c|c|c|c|c|}
\hline & 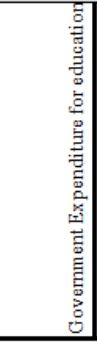 & 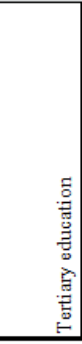 & 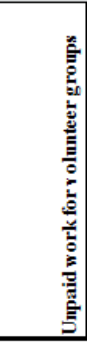 & 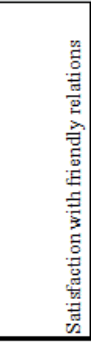 & 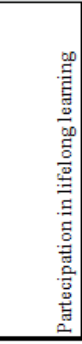 & 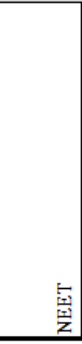 & 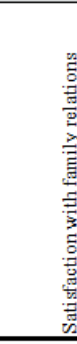 \\
\hline Piemonte & $-8,01$ & 47,1 & $-1,6$ & $-6,7$ & 72,9 & 48,1 & 0,81 \\
\hline Valle d'Aosta & $-4,86$ & 57,0 & 5,6 & 2,2 & 82,7 & 66,5 & 4,79 \\
\hline Liguria & $-11,60$ & 39,3 & 20,2 & 0,8 & 59,6 & 23,4 & $-2,37$ \\
\hline Lombardia & $-8,19$ & 65,1 & 2,2 & $-4,1$ & 69,5 & 46,1 & 0,78 \\
\hline Trentino Alto Adige & $-15,72$ & 95,3 & 6,7 & $-11,3$ & 50,3 & 34,3 & 0,25 \\
\hline Veneto & $-7,11$ & 84,2 & 4,9 & 1,6 & 40,2 & 32,7 & 7,85 \\
\hline Fruli Venezia Giulia & $-13,38$ & 15,1 & 0,7 & $-3,7$ & 77,7 & 55,6 & $-6,47$ \\
\hline Emilia Romagna & $-5,83$ & 48,7 & $-1,7$ & $-8,1$ & 72,4 & 55,9 & $-8,46$ \\
\hline Toscana & $-11,18$ & 58,0 & 10,0 & $-14,0$ & 48,9 & 38,2 & $-3,29$ \\
\hline Umbria & $-7,47$ & 56,7 & 21,8 & $-6,2$ & 46,5 & 28,4 & 2,51 \\
\hline Marche & $-4,46$ & 66,1 & 15,7 & $-6,3$ & 59,2 & 41,4 & 1,41 \\
\hline Lazio & $-10,17$ & 41,0 & 33,9 & $-10,6$ & 13,5 & 28,2 & $-3,30$ \\
\hline Abruzzo & $-18,91$ & 33,5 & $-19,1$ & $-2,7$ & 4,2 & 56,2 & 10,76 \\
\hline Molise & $-10,85$ & 67,5 & 68,5 & $-7,2$ & 1,2 & 26,2 & $-1,43$ \\
\hline Campania & $-14,57$ & 37,2 & 1,8 & $-16,2$ & 15,9 & 11,1 & $-9,91$ \\
\hline Puglia & $-15,81$ & 53,6 & 9,5 & 2,9 & 31,2 & 1,0 & 8,18 \\
\hline Basilicata & $-21,71$ & 88,7 & $-2,5$ & $-16,1$ & 30,9 & 4,4 & $-3,86$ \\
\hline Calabria & $-17,97$ & 79,0 & 11,3 & 14,2 & $-3,8$ & 27,3 & 12,49 \\
\hline Sicilia & $-13,78$ & 32,0 & 12,3 & $-8,6$ & 1,6 & 12,5 & $-2,55$ \\
\hline Sardegna & $-16,23$ & 90,6 & 11,7 & $-7,3$ & 64,4 & 24,7 & 7,74 \\
\hline
\end{tabular}

Source: Author's elaboration

More profoundly, starting from the Table 3.6 above, it is possible to observe that the educational indicators, like Tertiary education and Participation in lifelong learning, present an overall increments but there are significant territory variations, from 90 percentage points of Sardegna to 32 percentage points of Sicilia in Tertiary education, and from 77,7\% of Friulia - Venezia Giulia to 1,2 percentage points of Molise in Participation in lifelong learning.

A possible explanation of this phenomenon could be the following: according to the 
ROI Country Report: Italy $2017^{18}$ Nascia et al. 2017), in 2016 only 25\% of the Italian population (aged 25 - 34) attained tertiary education, putting Italy at the bottom of the European countries' ranking, well - below the EU 28 average of 38,2 percentage points. As a consequence, the major problem for Italy's high skilled human resources could be the growing number of graduates and researchers' emigration phenomenon: this phenomenon might represent a serious loss for Italy's research and innovation systems regarding the capacity of catching up with the rest of European research and innovation systems.

Regarding the social capital indicators' variations, Unpaid work for volunteer groups and Satisfaction with friendly relations show a cyclical trends: from $-19,1 \%$ of Lazio to $68,0 \%$ of Abruzzo in Unpaid work for volunteer groups from -16,2\% of Campania to 2,9\% of Puglia in Satisfaction with friendly relationsas it is possible to stress out from the previous Table 3.4. A possible explanation could be the presence of certain non-homogeneity degree and, in the same case the absence, of clear specialisation policies about the Smart Communities development by the regions themselves. But not all the Italian regions policies present this lack of clear policies; regions like Piemonte and Lombardia, present a considerable development about this theme. It is necessary to stress out that the presence in this region of this phenomenon, as it will be possible to notice in all the following parts of the present empirical analysis, has been encouraged by their technical, economic and administrative vocation to this Smart Communities phenomenon. Example of this strategic vocation is Lombardia, who results in the most Italian "smartness" region if it is considered the European standard performing measurement. Also, regions, like Emilia-Romagna, Veneto and Toscana are parts of this process, even if with a minor intensity.

Following, in the Table 3.6 below, it is possible to observe that there are significant increments in all the ICT-related indicators, like in Business $R \mathcal{E} D$ Expenditure and $R$ $\mathcal{E} D$ Personnel: from 78,0 of Emilia-Romagna to 25,5\% of Piemonte in Business $R \mathcal{E} D$ Expenditure, and from $99,9 \%$ of Trentino Alto Adige to $2,2 \%$ of Abruzzo for $R \mathcal{E} D$ Personnel.

18 The Research and Innovation Observatory (ROI) analyses and assess the development and the performance of national research and innovation systems and the related policies in the perspective of European Union strategies and goals. 
Table 6: Variations of ICT use and Innovation indicators from 2005 to 2016.

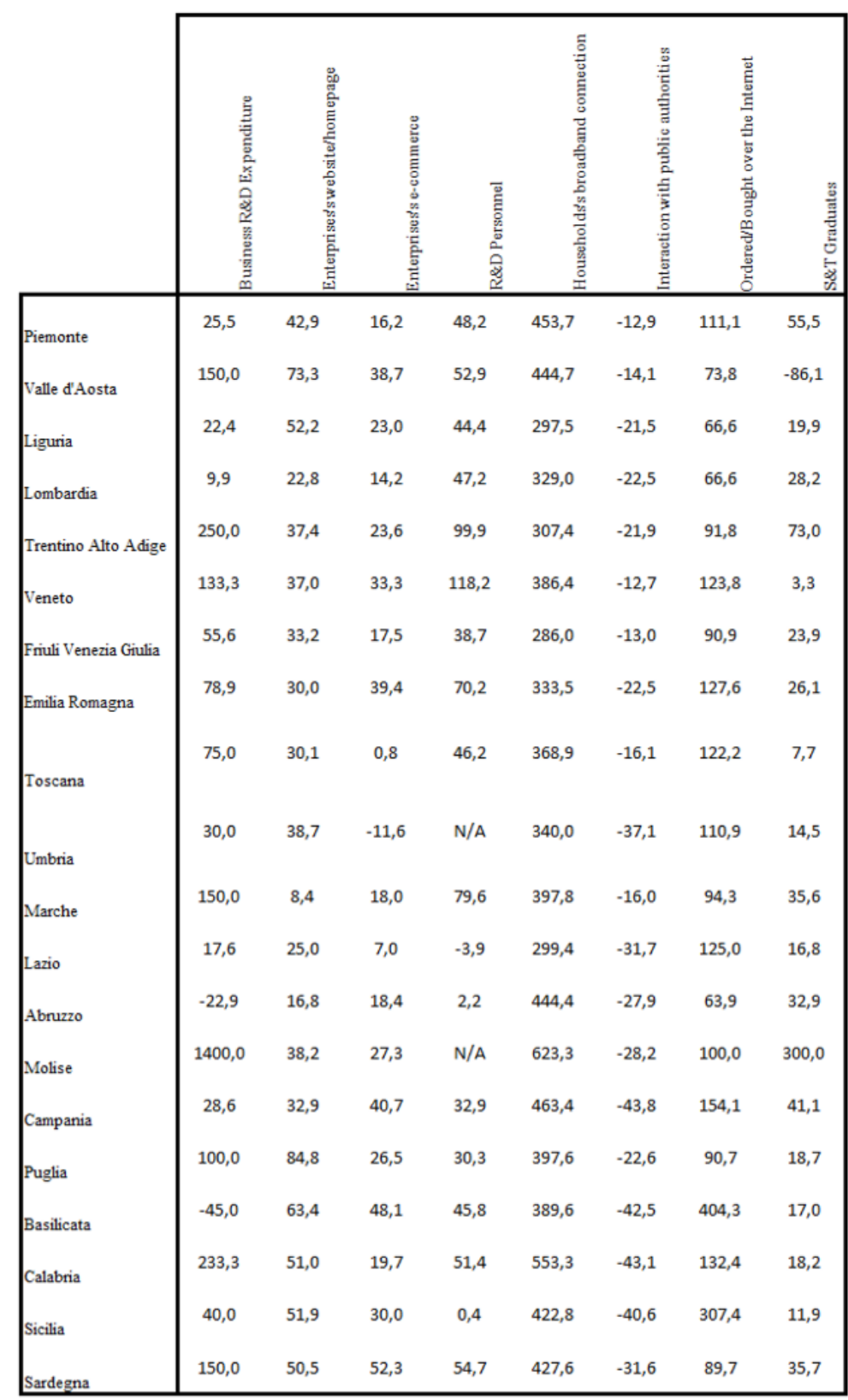

Source: Author's elaboration

In the last table, Table 3.7 below, it is possible to stress out the existence of cyclical trends for two out of three variables used for the analysis: from - $13,6 \%$ of Sicilia to $0,5 \%$ of Trentino Alto Adige in GDP per capitaand from -0,5\% of Sicilia to 5,3\% of Trentino Alto Adige with regard to Employment rate. 
Table 7: Variations of Economy indicators from 2005 to 2016.

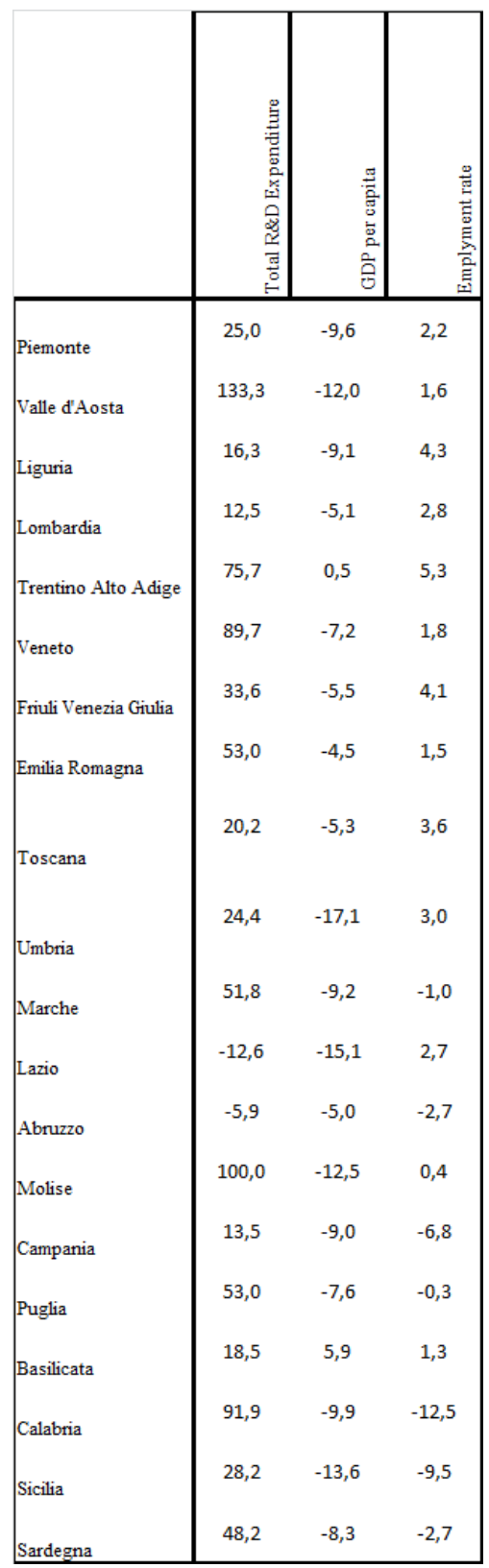

Source: Author's elaboration

Also here, it is possible to stress out some explanations about the analysed two previous macro - categories. The presence of this territory disparities could derive from the presence of low level of Business R \& D activities and on unfavourable framework conditions, putting Italy far below the European Union average: presence, in the Italian economic framework, of small and micro enterprises characterised by a low R \& D intensity, specialised in low-medium with technology products.

In particular, this phenomenon could be explained analysing, more deeply, four main frameworks: the economic context, the $R \mathcal{E} D$ funding, the Public allocation and $R \mathcal{E} D$ Expenditure and the Private $R \mathcal{E} D$ Expenditure. Starting from the economic contexts, the Employment in knowledge-intensive services sectors is showing, according to the Italian National Institute of Statistics, a decrease from 33,5 in 2015 to 32,2 in 2016. This negative employment trend in high-tech and high knowledge sectors points out the existence of 
the Italian economy's structural problems ${ }^{19}$. It is possible to stress out, regarding the $R \mathcal{E} D$ funding trend, a slower increase, with a fall in 2016, of Total R \& D Expenditure (GERD) brings to an increment of $\mathrm{R} \& \mathrm{D}$ performance of firms (BERD), as it is possible to see from the Figure 3.20 below.

Figure 20. Total R \& D in Italy (GERD), R \& D performed by business (BERD) and appropriations in onvernment hidoet (GRAORD)

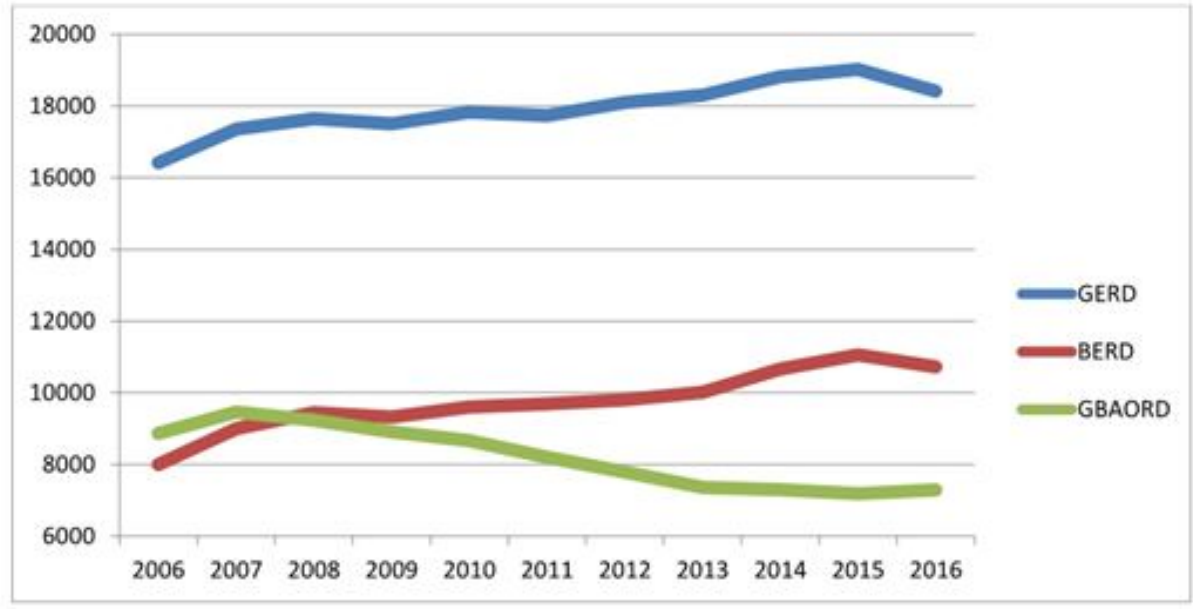

Source:ROI Country Report: Italy, 2017

Million euros at purchasing power standard at 2005 prices.

This increment, as a consequence, could drive the increase in spending ${ }^{20}$.Following, in the explanation of the possible cause, it is possible to notice that, since the start of the crisis in 2008, Total R \& D Expenditure and Business R \& D Expenditure have seen a significant reduction: in 2016 they were about $23 \%$ percentage points lower than in 2007. This reduction in public expenditure could be one of the principal cause of the researches' decline for the other $\mathrm{R} \& \mathrm{D}$ activities. This reduction has affected public and private research programmes: support for Business R \& D Expenditure has taken in the form of tax reduction. This R \& D tax credit expenditure schema became operation in 2015. It allowed $25 \%$ of a tax credit ${ }^{21}$ for incremental investments in R \& D (rising to $50 \%$ when $\mathrm{R} \& \mathrm{D}$ is carried in cooperation with the public) up to a maximum annual amount of 5 million for each beneficiary. Regarding the Business R \& D performance, as a share of GDP, it is $0,75 \%$ in 2010 , showing a modest increase over the past periods and a reduction, compared to 2015 . As it is possible to stress out, Italy remains far from the $R$ \& D effects of firms present in the other EU economies, like France and Germany, where their R \& D share is close to 1,5\% and 2,0\% respectively.

Carrying on the analysis with the second step through the use of the SOM algorithm, the Figure 3.21 below shows the location of Italian regions in 2005 - 2010 (a) and the analogue in 2011-2016 (b) ${ }^{22}$.

19 There is a lower presence of high - tech manufacturing and service industries compared to the other major European economies.

20 Conversely, budget appropriation for public R \& D in 2016 had lost about 2,000 million out of 9,000 million of 2007, as it is possible to figure out from the table.

21 The Stability Law of December 2016 extended the R \& D tax credit schema to 2020, incrementing the supporting to 50\% of incremental R \& D investments and setting a maximum amount of $20 €$ million for each beneficiary. Follow that the Stability Law of December 2017 maintained this incentives and extended the support for investment in new technologies trough the Industry 4.0 initiative.

22 The properties of the algorithm, as explained in the section two of this chapter, leads this map to represent the statistical property of the original dataset used to create it. 
Figure 21. Fvolution of the datahase from 2005 to 2016

(a)

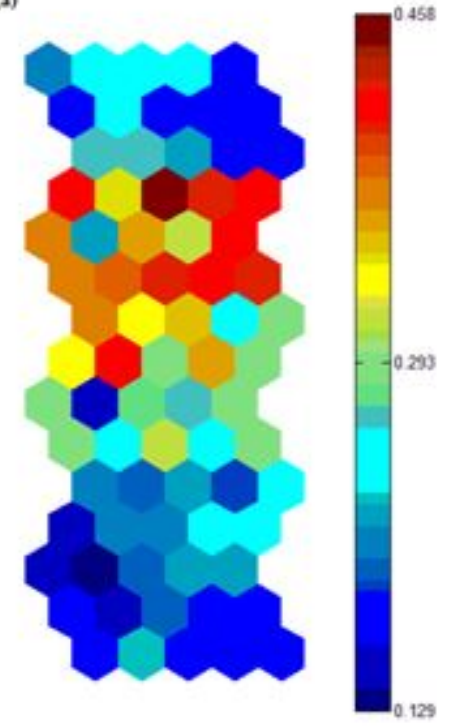

(b)

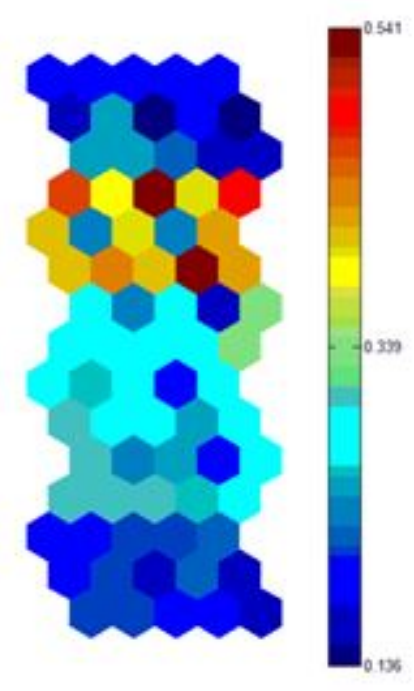

Source:Author's elaboration

This displacement has the effect of isolating the Southern regions from the Northern one, which remains, respectively, at the upper and bottom part of the map. As a consequence, it has created a gap between them and the rest of the sample ${ }^{23}$.

In 2016, this type of isolation causes the closeness of the Central regions to the Northern ones.

Following, it has separately analysed the period 2005-2010 and 2011-2016 through the use of their feature maps. Starting with the period 2005-2010, Figure 3.22 below shows the feature maps for every sixteen variables used. The values are displayed on a gradient colour range, from the blue (the lowest) to red (the highest). This tool also permit to:

1. To obtain different profiles for the regions of the SOM;

2. To discover in which socio-economic aspects the Italian regions are strong or weak;

3. To understand by which means the feature maps drive the final result.

23 In this context, statistical dissimilarity is translated into space distance and vice-versa. This feature is obtained due to the learning nature of the algorithm, as it was explained in the Section 2 of this chapter. Also, it is possible because the dataset has been mapped onto the surface of the SOM by adding each neurons up to color gradient. This map helps to define the agglomeration of the Italian regions. In this case, the color of the cells on the map represents the intra-cluster homogeneity degree: the cold colors represent a lack of homogeneity while the warm colors reveal the higher inter-cluster homogeneity degree. 
Fio11re 22. Featiure manc of the variahlec $-2005 / 2010$

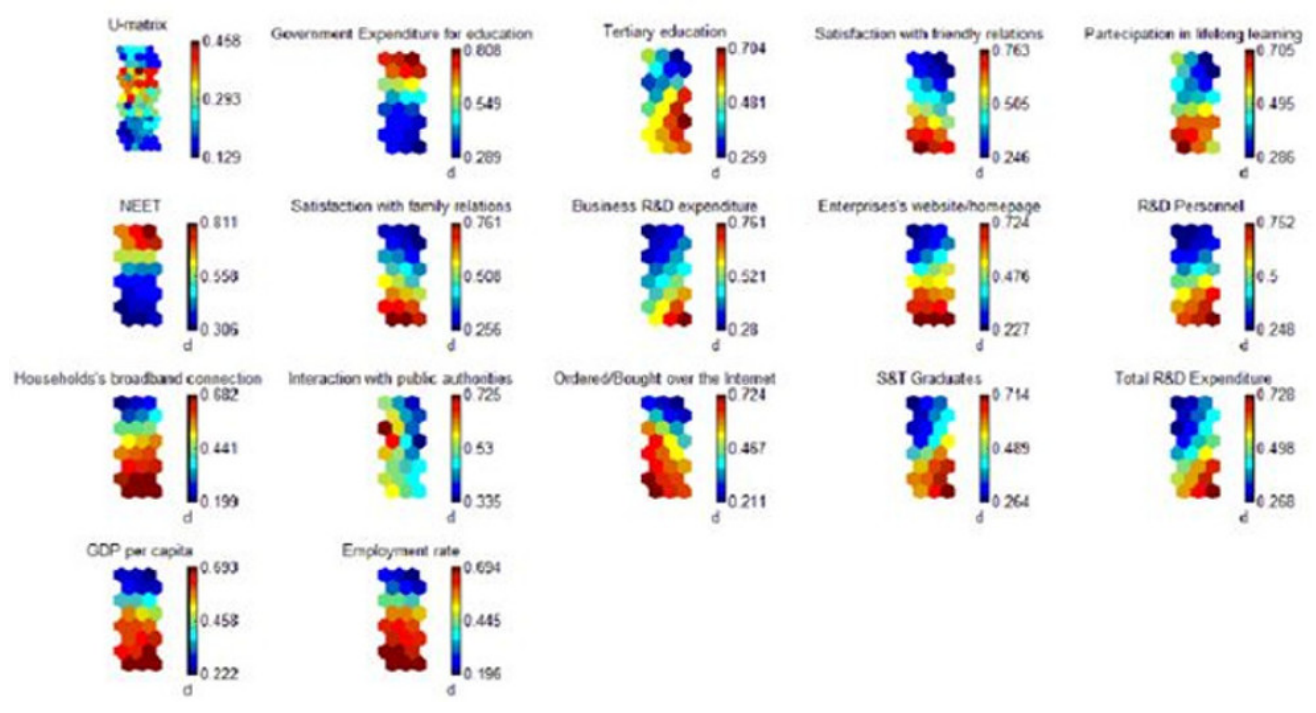

Source:Author's elaboration

It is possible to observe that Northern Italian regions, located at the bottom of the map, excel in nearly all considered variables. As profiled before in Figure 3.22, the Southern Italian regions, clustered in the upper part of the maps, show low values in all considered variables. In contrast, Northern regions, such as Piemonte, Lombardia and Friuli Venezia Giulia; and some Central regions, like Emilia Romagna and Lazio, obtain similar final results due to the high score in Business $R \mathcal{E} D$ Expenditure, $R \mathcal{E} D$ Personnel and Total $R$ $\mathcal{E} D$ Expenditure, but they poorly performance in Household's broadband connection and Employment rate.

Following the same type of analysis used above, Figure 3.23 below shows the feature maps of the variables during the period 2011- 2016.

Fionre 73 Feation manc of the variahlec - $7011 / 2016$
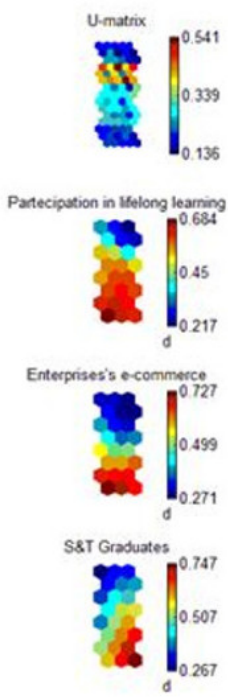
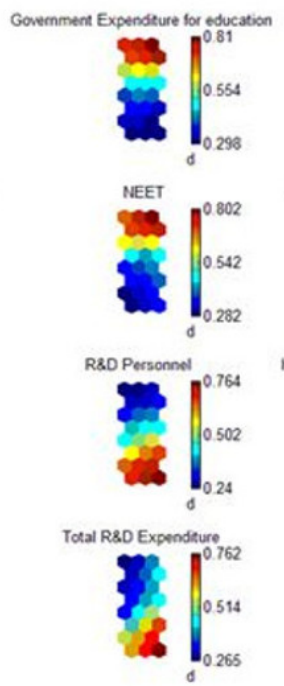
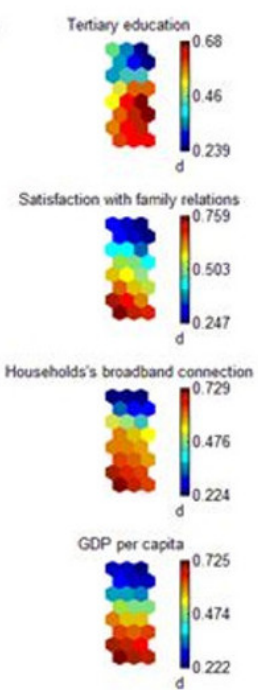
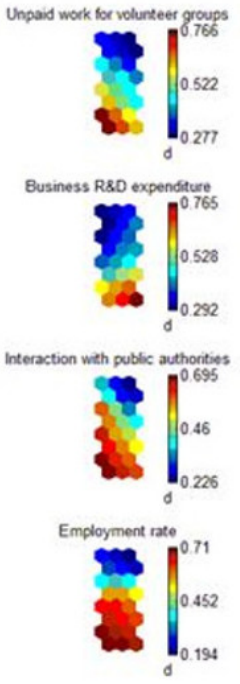
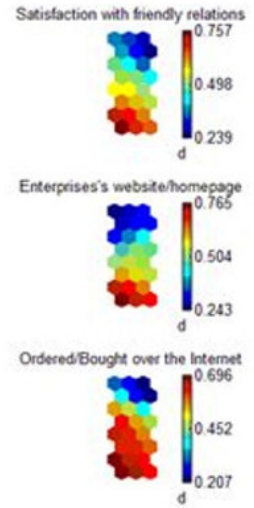

Source:Author's elaboration

In this figure, it is easy to observe that the Central and the Northern Italian regions, at the bottom of the map, present high values in all the variables. As for the previous period of analysis, 2005 - 201, the Southern Italian regions have low values in all the considered variables. Instead, Northern and part of the Central one, like Liguria, Toscana 
and Lazio; obtain similar results due to a high level of Business $R \mathcal{E} D$ Expenditure, Enterprises' website/homepage, Satisfaction with family relation and Participating in lifelong learning. For the entire period, 2005 - 2016, also, it is possible to stress out the presence of correspondences schemas between four pair $\mathrm{s}$ of variables. The first correspondence is between Government Expenditure on education and NEET proxies. For both variables, the Southern Italian regions have highlighted the greater incidence over the Government Expenditure on education and a double one over NEET respect to the North-West.

What emerged from that type of correspondence is the possible presence of a severe divergence in the educational performances: the South regions might show poorer performances that might lead to unequal opportunities for the young people in the Southern regions. A possible explanation for this phenomenon could be the so-called Italian work where Putnam, Leonardi and Nanetti (1993) attribute the presence of these disparities, mostly, to a significant difference between the level of civic engagement in Northern and Southern Italy. The researchers stressed the idea that the tendency of civic associations in the north of Italy to facilitate the creation of dense horizontal networks and many opportunities for people to learn about trust and social norms. This correspondence reinforces the idea which views the institutional trust between citizens and local government is higher in Northern Italy relative to Southern ones.

The second general correspondence is between Tertiary education, $S \mathcal{E}$ T Graduate, Business $R \mathcal{E} D$ Expenditure and Total $R \mathcal{E} D$ Expenditure: from these correspondences it is possible to stress out how the innovative activities could be seen as a crucial factor for the enterprises' competitiveness impacting substantially on the products and/or processes innovation: the bridging - type's relations facilitate the diffusion of non-redundant knowledge and trust - building between heterogeneous groups. In fact, in 2015 the North-West, with its 36,2 percentage points of total GDP, has the larger share of the Italian R \& D Expenditure; and in particular Piemonte, Trentino Alto Adige and Emilia Romania. The third correspondence is between GDP per capita and Employment rate proxies.For both variables, the Northern and the Central regions have highlighted greater incidence: where there are higher productivity and innovation vocations, this is reflected into a high rate of employability. The last correspondence is between Satisfaction with friendly relations and Satisfaction with family relations:according to Zheng (2010), the network size affects innovation by the availability of a large and, probably, the different volume of information and resources, helping in the formation of new ideas and potential availability of innovation resources. What emerged from the previous two analyses is the presence of regional disparities: suffering from laze divergences between the North and the South of Italy concerning economic structures, technological activities and employment rate. There are, also, severe disparities between Northern and Southern Italian regions regarding Regional Innovation Systems activities: the R \& D Expenditure on regional GDP is $1,4 \%$ in the North and $0,9 \%$ in the South.

It follows that regional imbalance in innovation has severely increased with two third of innovation firs and three-quarters of Total $R \mathcal{E} D$ Expenditure concentrated in only 5 regions:

1. Lombardia with $25 \%$ of innovations;

2. Veneto;

3. Emilia Romagna;

4. Piemonte;

5. Lazio.

instead, under the social capital effect point of view, it is possible to stress out that the bridging social capital dimension could be a crucial factor for the regional diversification because they act as s bridge between disconnected activities and as well as to enable the creation of new combinations of different standards of knowledge and capabilities: all of these dynamics boost the regional diversification, increasing the probability of developing new specialization in the Italian context, but also, in Europe, through the 
acquisition of new industrial specialization ${ }^{24}$.

What about the other social capital dimension? Regarding the bounding social capital dimension, it could be potentially detrimental for the ability of regions to adapt and introduce new products: strongly embedded in the local economy, local activities might have a harder time to make crossover mobilisation and the combination of different skills and head necessary efforts to diversify.

As it is possible to see, both positive and negative effects, the two sides of informal institutions, enable regions to allow to stay less closed to their existing activities when they diversify into new industries.

Following the analysis with the third step through the multivariate regression model, the theoretical model between social capital and digital infrastructures and the level of income in the region, introduced in the Methodology section and derived from the regional income inequality model, could be tested empirically using the Italian regional panel data from 2006 to $2013^{25}$.

To obtain the estimating equation, equation 3.8 is transformed by adding time subscripts and the error term. This allows empirical equation 3.9 to be obtained, i.e. a logarithmic relationship between income per worker and factor endowments in the 's region at time , including digital and social capital infrastructures. This relationship becomes:

$$
q_{i t}=\phi_{t}+\alpha_{i t}+\beta_{1} l_{i t}+\beta_{2} h_{i t}+\beta_{3} p_{i t}+\beta_{4} t_{i t}+\beta_{5} s_{i t}+\epsilon_{i t}
$$

where $\phi_{t}$ is a factor common to all regions that depends on the variables not included in to the regression model, and the lower letters denote the logarithms of $A, L, H, P$, $T, S$ respectively, while $\epsilon$ is the error term. The expected signs of parameters on the explanatory variables in equation $3: 6, \beta_{1}>0, \beta_{2}>0, \beta_{3}>0, \beta_{4}<0$ and $\beta_{5}<0$. To estimate these parameters, standard fixed and random effect panel data techniques are used (Hsiao, 1986).

The primary advantage of the panel data approach over previous studies based on simple OLS methods is that it allows the reduction of the effects of the omitted variables bias that may arise in cross-section regressions and the sample choice was determinate by data availability. The sample is limited upwards to 2007 because this was the first year where all selected variables are present. The dependent variable used measures the regional income per capita $q_{i t}$ and the estimating equation used five explanatory variables representing regional characteristics and the objects of the analysis: $l_{i t}, h_{i t}$, $p_{i t}, t_{i t}$ and $s_{i t}$ The main explanatory variables are the innovation level, represented by Business $R \mathcal{E} D$ Expenditure, in the region $i$ at time $t$ and $t_{i t}$, the friendly satisfaction level, representing the social capital level, in the region $i$ at time $t$ and $p_{i t}$ and the ICT level, represented by the Household broadband connection, in the region $i$ at time $t, s_{i t}$.

Data on employment in region lit concern all people who perform work that yields income and the educational level, $h_{i t}$, in the region was proxied by the population aged 30-34 with tertiary education. The choice of this proxy is motivated by the fact that the majority of young people who graduate from university constitute a pool of future highly skilled labor force.

Descriptive statistics on the variables used in estimating equations are shown the following Table 3.8.

24 This phenomenon could be stronger in regions whit poor government quality.

25 As stated in the Methodology section, this model is based on the two-stage production process. This process, modelled using a nested regional production function, assumes that a number of geographically disperse firms within region produce intermediate inputs that are then supplied to final good producers. 
Figure 24 Variahles 11sed in the emnirical sti1dve nonled data s11mmarv statictics

\begin{tabular}{|c|c|c|c|c|c|}
\hline Variable & Measure & Mean & $\begin{array}{l}\text { Standa } \\
\text { id } \\
\text { deviatio } \\
\text { n }\end{array}$ & Minimum & Maximum \\
\hline GDP per capita & $\begin{array}{l}\text { euro in chain-linkingvalues - } \\
\text { reference year } 2010\end{array}$ & $\begin{array}{r}26217 \\
.91\end{array}$ & 6614.302 & 15440.74 & $\begin{array}{r}36892.2 \\
9\end{array}$ \\
\hline Employment rate & percentage values & $\begin{array}{r}61.80 \\
071\end{array}$ & 9.398 & 42.31 & 74.223 \\
\hline $\begin{array}{l}\text { Population aged } 30-34 \text { with } \\
\text { tertiary education }\end{array}$ & percentage values & 20.22 & 3.830 & 12.571 & 28.728 \\
\hline Business R\&D Expenditure & percentage of GDP & 0.465 & 0.347 & 0.02 & 1.56 \\
\hline Friendly relations & percentage values & 26.01 & 4.236 & 15.5 & 35.8 \\
\hline Household broadband & $\begin{array}{l}\text { Percentage of hous ehold with the } \\
\text { same characteristics }\end{array}$ & $\begin{array}{r}35.70 \\
75 \\
\end{array}$ & 15.083 & 8.6 & 65.9 \\
\hline
\end{tabular}

Before turning to the panel data approach, as a useful point of reference, the results obtained using pooled data and considering, as constant, the time effect for all regions are also presented. This last type of approach assume that time effect are changeable during time and constant for all Italian regions. The estimated values of the model parameters from equation 3.9 are given in table 3.8.

The previous two policy responses are just included in the Industry 4.0 Strategy which provide a new focus for the previous measurement. It identifies new targets regarding public and private investments, included the technological educational programmes, that combine a wide range of policy tools like:

1. 3,5 billion will be available between 2017 and 2020 for Digital Chain infrastructures, targets for 2020 include access for all firms to $30 \mathrm{Mbps}$ bandwidth network and access for $50 \%$ of firms to the $100 \mathrm{Mbps}$ bandwidth networks;

2. $250 €$ million is allocated to tax benefits for the training of the employees involved in the technologies supported by Industry 4.0 Strategy

Its implementation is still at an early stage at both nation and regional level and, at the same time, the reducing of the divergence between RIS's systems in Northern and Southern of Italy will continue to represent the major policy challenge and relevant new insights could be obtained by future researches focused on these issues: R \& D could be considered as a relevant predictors of innovation outcomes but the investment effort in $\mathrm{R} \& \mathrm{D}$ it is not itself enough to achieve innovation outcome in regions with low level of social capital and ICT use. As a consequence, R \& D inputs should be accompanied by effort to promote social capital and ICT. In this framework, Sicilia and Abruzzo might be considered a good examples for the implementation of R \& D investments even if the almost or total absence of social capital.

\section{Conclusions}

As it was possible to stress out from all the present research work, the evolutionary economic geography literature has renewed interest on firms, on their organisation routines and knowledge and the self- sustaining development dynamics, rose from their co-location within the regions. Along with the positive aspects highlighted in Chapter 1, various authors, like Weber and Rohracher (2012), have identified series of structural system failures, which inform and shape system - oriented public policy support for innovation.

This new type of territorial capital could be fundamental for the individual development strategies which aim is to attract new activities and take the most from its regional/territorial assets.

Funding: This research received no external funding

Conflicts of Interest: The author declares no conflict of interest. 


\section{References}

Boschma, R. Proximity and innovation: a critical assessment. Regional Studies 39(1), pp. 61- -74.

Cohen, W.; Levinthal, D.Innovation and learning: the two faces of R \& D Economic Journal 1989, 99(39), 569-596.

Cooke, P.; Asheeim, B.; Boschma, R.; Martin, R.; Schwartz, D.; Tödtling, F. Handbook of Regional Innovation and Growth, Edward Elgar, London, United Kingdom.

De La Fuente, A. On the sources of convergence: a close look at Spanish regions. European Economic Review 2002, 46, 560-599.

De La Fuente, A.; Vives, X. Infrastructure and education as instruments of regional policy: evidence from Spain. Economic Policy 1995, 10(20), 13-51.

Dicken, P. (2007). Global Shift: Mapping the changing contours of the world economy, Newbury Park CA: Sage, California, USA, 2007.

Hall, R.E.; Hardy, S. RSA annual conference. Building entrepreneurial capacity in the regions. Regions 1999, 243.

Hall, R.E.; Jones, C.L. Why Do Some Countries Produce so much more output per Worker than Others?. Quarterly Journal of Economics 1999, $114(1), 83-116$.

Kroll, H. Implement smart specialization in practice-leading unlike horses to the water. European Planning Studies 2015, 23(10), 2079-2098.

Sassen, S. (2003). Agglomeration in the digital area ibution. In Cybercities Reader; Grahan,S., Ed.; Routledge: London, United Kingdom, pp. 191-199;

Schumpeter, J.A.The theory of economic development, Harvard University Press, Cambridge, MA, USA. 